\title{
Article \\ Strategic Integration Decision under Supply Chain Competition in the Presence of Online Channel
}

\author{
Subrata Saha ${ }^{*}+\left(\right.$ ib and Izabela Nielsen ${ }^{+}$(i) \\ Department of Materials and Production, Aalborg University, DK 9220 Aalborg East, Denmark; \\ izabela@mp.aau.dk \\ * Correspondence: saha@m-tech.aau.dk; Tel.: +45-9193-9202 \\ + These authors contributed equally to this work.
}

Citation: Saha, S.; Nielsen, I. Strategic Integration Decision under Supply Chain Competition in Presence of Online Channel. Symmetry 2021, 13, 58 . http://doi.org/10.3390/sym13010058

Received: 10 December 2020 Accepted: 29 December 2020 Published: 31 December 2020

Publisher's Note: MDPI stays neutral with regard to jurisdictional clai$\mathrm{ms}$ in published maps and institutional affiliations.

Copyright: () 2020 by the authors. Licensee MDPI, Basel, Switzerland. This article is an open access article distributed under the terms and conditions of the Creative Commons Attribution (CC BY) license (https:// creativecommons.org/licenses/by/ $4.0 /)$.

\begin{abstract}
This study explores the pricing decisions of substitutable products for two competing supply chains in the presence of an online channel. Each supply chain consisting of a single manufacturer and an exclusive retailer and one of the manufacturers distributes products through the online channel. We examine optimal decisions under five scenarios to explore how the strategic cooperation between two manufacturers at the upstream horizontal level or with the retailer at the vertical level affects product pricing decisions and the performance of two supply chains? The results reveal that decisions for cooperation with competing manufacturers and opening an online channel are correlated. In the absence of an online channel, cooperation with their respective retailer can lead to a higher supply chain profit. However, if a manufacturer opens an online channel, then cooperation with competing manufacturers can lead to a higher supply chain profit. Under the vertical integration, total supply chain profit might be lower compared to a scenario where members in each supply chain remain independent. Consumers also need to pay more for products.
\end{abstract}

Keywords: dual-channel supply chain; substitute products; strategic integration; competition

\section{Introduction}

Direct-sales strategies are gaining popularity among manufacturers, particularly after the enormous rise in internet and web technology use due to easy accessibility. Many manufacturers sell their products through the traditional retail store as well as through an online channel [1-3]. Based on the statistics of the U.S. Department of Commerce, consumers spent $\$ 601.75$ billion online with U.S. merchants in 2019 , up $14.9 \%$ from $\$ 523.64$ billion the previous year [4]. Examples of direct selling commonly seen in practice: firms such as Apple, Nike, and Microsoft sell their products through brick-and-mortar stores as well as their online channels. Although direct selling may threaten downstream retailers by reducing their market share, researchers have reported that it can also increase the retailer's profit under the price [5] or quantity [6] competition. Moreover, product information from an online channel can improve the performance of retail operations [7,8]. Over the past two decades, a large number of researchers have focused on exploring the characteristics of supply chain(SC) decisions in the presence of an online channels from various perspectives, such as consistent or inconsistent pricing decision in both retail and online channels [5,9-11], product quality decision [12], the effect of free-riding [13], assortment decision [14], retailer's service effort [15], cooperative advertising decision [16,17], inventory decision [18], carbon emission reduction decision [19], the effect of disruption [20], information asymmetry [21,22], green-product retailing [23], re-manufacturing decision [24] etc. However, the characteristics of the manufacturer's decision to open an online channel and strategic integration decisions under competition are not well documented in the literature.

Presently, a combination of offline and online marketing strategies gaining significant popularity to reach larger consumers and deliver a product with the greatest impact. In this study, we analyze the equilibrium of two competing SCs, both consisting of a single 
manufacturer, selling its substitute products exclusively through a single retailer, and one of the competing manufacturers sells products online also. The proposed competing SC structure fits industries such as premium gasoline, garments, footwear, travel accessories, health and beauty products, health care, electronics accessories, etc., where a manufacturer trades with an exclusive retailer and faces strict competition due to the presence of other firms. Over the past three decades, the optimal decisions in a two-manufacturer-tworetailer SC competition have been studied by several researchers [25-29] under the various game-theoretic frameworks. Under competition, as a strategic decision, integration with a horizontal competitor or 'collusion formation' [30-32] is not unusual in today's business environment. Competing members are interested in strategic integration in anticipating the achievement of business goals such as increasing the current joint market size, developing products with new features to protect the present and future share of the market, and to conquer a larger share of the market that remains unexplored [33]. However, the literature on horizontal integration in the presence of an online channel is scanty and there has been little analytical research in this direction so far. This study aims to understand the combined effect of strategic integration decisions at both the horizontal and vertical levels in the presence of an online channel. Specifically, we attempt to answer: How do potential use of the direct selling channel under competition and strategic integration decision at horizontal and vertical levels affect:

(a) competing manufacturers' and retailers' strategies in equilibrium;

(b) the equilibrium price in the online and retail channels, and wholesale prices;

(c) the total profits for each SCs?

To study the combined effect, we derive the optimal decision in five different scenarios. First, we derive results for the benchmark scenario; we name it Scenario BM, which represents a competing SC model in the absence of an online channel. The remaining four scenarios are somewhat close to [31,32]; however, the authors investigated pricing decisions in the absence of an online channel. We consider Scenario DD, where the first manufacturer sells products through retail and online channels. We compare outcomes between Scenarios $\mathrm{BM}$ and DD to explore whether opening an online channel is profitable for a manufacturer under competition. Next, we consider Scenarios II and ID, representing the instances when members in each SC are vertically integrated and members in the first SC are vertically integrated, respectively [34]. Finally, we explore the optimal decision under Scenario UC to study the effect of cooperation at the upstream level between two manufacturers.

Our main contributions are as follows: First, only a few researchers in the literature explored the pricing problem of substitutable products under SC competition in the presence of an online channel. Recently, ref. [35] made an effort in this direction, but the authors considered a two-manufacturer-single-retailer SC setting. Second, although strategic integration decisions both at the horizontal and vertical levels are studied by researchers and practiced in the business world, a complete overview regarding their impact in the presence of a dual channel under SC competition is missing. We found that the first manufacturer's decision to open an online channel makes an enormous impact; in some parameter settings, it is completely different if the online channel does not exist. Indeed, to soften the competition at the downstream level, two manufacturers can cooperate with each other's at a horizontal level for ensuring higher profits. Except in Scenario UC, two retailers can set different product prices. Third, we also draw insights into how cross-price elasticity between online and retail channels or in between two retail channels have affected the strategic integration or the manufacturer's decision for opening a direct channel. We find that when the cross-price elasticity between retail and online channels is low, the manufacturer might not sell directly to the end customers.

The remainder of this paper is organized as follows. We introduce the problem scenarios and corresponding assumptions and notation in Section 2. Section 3 introduces our five models and corresponding comparative analysis. In Section 4, we summarize managerial insights into the study. Finally, we conclude in Section 5 by highlighting 
limitations and future research directions. All key proofs and additional symbols used to represent analytical expression are provided in the Appendix $\mathrm{H}$.

\section{Problem Statement}

We consider two competing SCs $(i=1,2)$, each consisting of a manufacturer $\left(M_{i}\right)$ and an exclusive retailer $\left(R_{i}\right)$. We assume the manufacturer $M_{1}$ sells products through $R_{1}$ and $M_{2}$ sells the product through $R_{2}$, respectively, and cross-selling activity between two SCs is not allowed [31,32].

We investigate the optimal decisions under five decision scenarios ( $j=\mathrm{BM}, \mathrm{DD}, \mathrm{II}, \mathrm{ID}$, UC) as presented below in Figure 1:

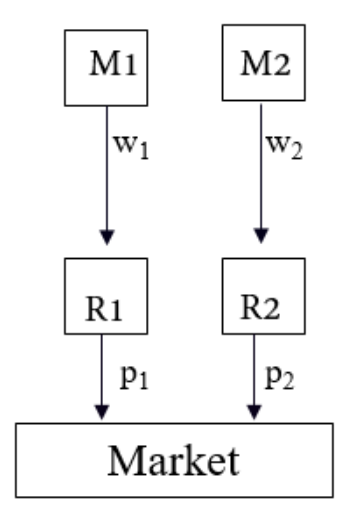

Scenario BM

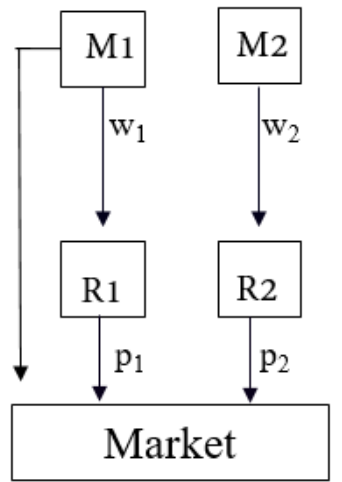

Scenario DD

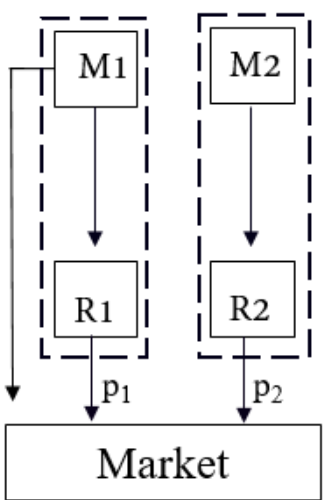

Scenario II

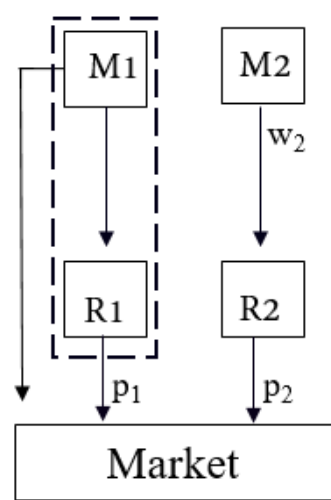

Scenario ID

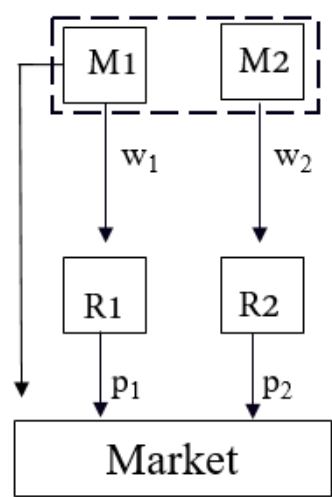

Scenario UC

Figure 1. Various scenarios considered in this study.

In Scenario BM, each member in competing SCs implements a non-cooperative decision in the absence of an online channel, which is similar to [32,34]. In Scenario $D D$, members remain non-cooperative, but the manufacturer in the first SC opens an online channel. Therefore, we compare the decisions in Scenarios BM and DD to verify whether opening an online channel is profitable for the first manufacturer. We derive optimal decisions in three scenarios, namely Scenarios $I I$ and $I D$, where members in each SC are vertically integrated and members in the first SC are vertically integrated, respectively. Finally, we explore the decision in Scenario UC, where two upstream manufacturers cooperate to maximize total upstream profits [31].

We assume $D_{1}^{j}$ and $D_{2}^{j}$ represent demand for products offered by the first and second manufacturer through the retail channels, respectively; and $D_{0}^{j}$ represents the demand for the product offered by the first manufacturer in the online channel. We consider the linear price-dependent demand model which is widely adopted in the literature [31,34].

$$
\begin{aligned}
& D_{i}^{j}=a \alpha-p_{i}^{j}+\beta_{1} p_{k-i}^{j}+\beta_{2} p_{0}^{j} ; \quad i=1,2 ; k=3-i \\
& D_{o}^{j}=2 a(1-\alpha)-p_{0}^{j}+\beta_{2} p_{1}^{j}+\beta_{2} p_{2} j ; \quad(0 \leq \alpha \leq 1)
\end{aligned}
$$

Therefore, we assume the potential demand (a) for both products remains the same [25,31] and in the presence of an online channel, a percentage of customers $(1-\alpha) \times 100 \%$ prefer an online channel. Competition exists among direct sale channel and retail channels. Furthermore, we assume the self-price effect is greater compared to the cross-price effect [32]. To focus on the effect of strategic cooperation on the decision for opening an online channel, we assume the two manufacturers are symmetric and production costs and operational costs for members are constant and normalized to zero. Assuming non-zero costs and symmetric demand will not qualitatively change our main results [36]. 
Retailer price for first product in an online channel must be greater than wholesale price, otherwise an infeasible scenario may be encountered by the first retailer. In addition, we assume that all information among participating members between two SCs is symmetric and members are risk-neutral [19,37-39]. To ensure the existence and feasibility of equilibrium solutions, we make the following assumptions: $2>\beta_{1}^{2}+\left(3+2 \beta_{1}\right) \beta_{2}^{2}$; $8>5 \beta_{1}^{2}+\left(13+10 \beta_{1}\right) \beta_{2}^{2} ; 1>\beta_{1}^{2}+2 \beta_{1}^{4} ; 16>17 \beta_{1}^{2}-4 \beta_{1}^{4}+\left(26+\beta_{1}\left(20-\beta_{1}\left(11+8 \beta_{1}\right)\right)\right) \beta_{2}^{2}$. All the propositions proposed in this study presuppose these conditions.

With the above assumptions and notations, profit functions for two retailers and two manufacturers in competing SCs are formulated as follows:

$$
\begin{gathered}
\Pi_{r i}^{j}=\left(p_{i}^{j}-w_{i}^{j}\right) D_{i}^{j}, i=1,2 \\
\Pi_{m 1}^{j}=\Pi_{m 1 r}^{j}+\Pi_{m 1 o^{\prime}}^{j} \quad \text { where } \Pi_{m 1 r}^{j}=w_{1}^{j} D_{1}^{j} \\
\Pi_{m 1 o}^{j}=p_{o}^{j} D_{o}^{j} \\
\Pi_{m 2}^{j}=w_{2}^{j} D_{2}^{j}
\end{gathered}
$$

All common parameters and variables mentioned in this study are clearly listed in Table 1.

Table 1. Notations.

\begin{tabular}{ll}
\hline Notations & Descriptions \\
\hline $\begin{array}{l}\text { Indices } \\
j\end{array}$ & $\begin{array}{l}\text { index for ith } S C, i \in\{1,2\} \\
\text { index for decision scenarios, } j \in\{B M, D D, I I, I D, U C\}\end{array}$ \\
$\begin{array}{l}\text { Parameters } \\
\beta_{1}\end{array}$ & market potential for each SC \\
$\beta_{2}$ & the cross-price sensitivity of consumers between two retail channels, $\beta_{1} \in[0,1)$ \\
Variables & the cross-price sensitivity of consumers between retail and online channels, $\beta_{2} \in[0,1)$ \\
$w_{i}^{j}$ & wholesale price of per unit $i$ th product \\
$p_{i}^{j}$ & retail price of per unit $i$ th product in the traditional retail channel \\
$p_{o}^{j}$ & retail price of per unit first product in the online channel \\
$\Pi_{r i}^{j}$ & profit of the $i$ th retailer \\
$\Pi_{m 1}^{j}$ & profit of the first manufacturer, i.e., sum of profits from the retail channel $\left(\Pi_{m 1 r}^{j}\right)$ and online \\
$\Pi_{m 2}^{j}$ & channel( $\left.\Pi_{m 10}^{j}\right)$, and $\Pi_{m 1}^{j}=\Pi_{m 1 r}^{j}+\Pi_{m 10}^{j}$ \\
$\Pi_{c 1}^{j}$ & profit of the second manufacturer \\
$\Pi_{c 2}^{j}$ & profit of the first $S C$, i.e., sum of profits form the retail channel $\left(\Pi_{c 1 r}^{j}=\Pi_{m 1 r}^{j}+\Pi_{r 1}^{j}\right)$ and online \\
$Q_{i}^{j}$ & channel $\left(\Pi_{m 10}^{j}\right)$, and $\Pi_{c 1}^{j}=\Pi_{c 1 r}^{j}+\Pi_{m 1 o}^{j}$ \\
\hline
\end{tabular}

In the following section, we present the optimal decisions in five scenarios.

\section{Main Analytical Results}

In this section, we discuss the characteristics of the optimal decisions in five scenarios. In the first subsection, we present two benchmark decentralized models, i.e., Scenarios BM and DD. In the next subsection, we present three models representing the possibilities of two vertically integrated scenarios, i.e., Scenarios II and ID. Finally, we present the model in Scenario UC. 


\subsection{Benchmark Models}

\subsubsection{Optimal Decisions in Scenario BM}

Scenario BM is similar to the existing studies on SC competitions in the absence of an online channel. Two upstream manufacturers dominate two SCs, i.e., two manufacturers act as the Stackelberg leaders [32,34], and set wholesale prices $\left(w_{i}^{b m}\right)$ by maximizing their respective profits. Then, two downstream retailers determine market prices $\left(p_{i}^{b m}\right)$ to maximize their respective profits. By using the two-stage optimization technique, the optimal equilibrium solution is obtained. The optimization problem in Scenario BM is as follows:

$$
\left\{\begin{array}{c}
\max _{w_{1}^{b m}} \pi_{m 1}^{b m} \max _{w_{2}^{b m}} \pi_{m 2}^{b m} \\
\left\{\max _{p_{1}^{b m}} \pi_{r 1}^{b m} \max _{p_{2}^{b m}} \pi_{r 2}^{b m}\right.
\end{array}\right.
$$

Therefore, in this scenario $\alpha=1, p_{o}^{b m}=0$, and $\beta_{2}=0$. Optimal decisions in Scenarios $\mathrm{BM}$ are presented in Propositions 1 and we refer to Appendix A for the detailed derivation of results.

Proposition 1. Optimal decision in Scenario BM is obtained as follows:

$w_{i}^{b m}=\frac{a\left(2+\beta_{1}\right)}{\Delta_{b m}}, p_{i}^{b m}=\frac{2 a\left(3-\beta_{1}^{2}\right)}{\left(2-\beta_{1}\right) \Delta_{b m}}, \Pi_{r i}^{b m}=\frac{a^{2}\left(2-\beta_{1}^{2}\right)^{2}}{\left(2-\beta_{1}\right)^{2} \Delta_{b m}^{2}}, \Pi_{m i}^{b m}=\frac{a^{2}\left(2+\beta_{1}\right)\left(2-\beta_{1}^{2}\right)}{\left(2-\beta_{1}\right) \Delta_{b m}^{2}}$, $\Pi_{c i}^{b m}=\frac{2 a^{2}\left(6-5 \beta_{1}^{2}+\beta_{1}^{4}\right)}{\left(2-\beta_{1}\right)^{2} \Delta_{b m}^{2}}, Q_{i}^{b m}=\frac{a\left(2-\beta_{1}^{2}\right)}{\left(2-\beta_{1}\right) \Delta_{b m}}$, where $\Delta_{b m}=4-\beta_{1}-2 \beta_{1}^{2}$

Because $\beta_{1} \in[0,1)$, i.e., $\Delta_{b m}>0$ an optimal decision exists in this scenario. From Proposition 1, we made the following remarks:

Remark 1. Retail prices, sales volume, profits for both retailers and manufacturers increase with $\beta_{1}$, because $\frac{\partial p_{i}^{b m}}{\partial \beta_{1}}=\frac{4 a\left(9+\beta_{1}-6 \beta_{1}^{2}+\beta_{1}^{4}\right)}{\left(2-\beta_{1}\right)^{2} \Delta_{b m}^{2}}>0, \frac{\partial Q_{i}^{b m}}{\partial \beta_{1}}=\frac{2 a\left(6-\left(2-\beta_{1}\right) \beta_{1}\left(1+\beta_{1}\right)^{2}\right)}{\left(2-\beta_{1}\right)^{2} \Delta_{b m}^{2}}>0$, $\frac{\partial \Pi_{r i}^{b m}}{\partial \beta_{1}}=\frac{4 a^{2}\left(2-\beta_{1}^{2}\right)\left(6-\left(2-\beta_{1}\right) \beta_{1}\left(1+\beta_{1}\right)^{2}\right)}{\left(2-\beta_{1}\right)^{3} \Delta_{b m}^{3}}>0, \frac{\partial \Pi_{m i}^{b m}}{\partial \beta_{1}}=\frac{4 a^{2}\left(12+\left(2-\beta_{1}\right) \beta_{1}\left(3-\beta_{1}\left(1+\beta_{1}\right)\left(3+\beta_{1}\right)\right)\right)}{\left(2-\beta_{1}\right)^{2} \Delta_{b m}^{3}}>0$.

The results are consistent with the existing literature [31]. i.e., if cross-price elasticity increases, profits for each SC member increase due to price discrimination power. It is obvious that each manufacturer receives higher profits compared to each downstream retailer because $\Pi_{m i}^{b m}-\Pi_{r i}^{b m}=\frac{2 a^{2}\left(2-\beta_{1}^{2}\right)}{\left(2-\beta_{1}\right)^{2} \Delta_{b m}^{2}}>0$. We use outcomes in Scenario BM as a benchmark to examine: Is opening an online channel is profitable for an upstream manufacturer in the presence of SC competition?

\subsubsection{Optimal Decisions in Scenario DD}

In this scenario, one of the upstream manufacturers opens an online channel. For simplicity, we assume that the first manufacturer opens an online channel in anticipation of an increase in sales, and hence profits. The manufacturer $M_{1}$ sets wholesale price $\left(w_{1}^{d d}\right)$ and price for online channel $\left(p_{o}^{d d}\right)$ and the manufacturer $M_{2}$ sets wholesale price $\left(w_{2}^{d d}\right)$ by maximizing their respective profits. Then, two downstream retailers set their respective market prices $\left(p_{i}^{d d}\right)$ to maximize their respective profits. Therefore, the optimization problem in Scenario DD is as follows:

$$
\left\{\begin{array}{rr}
\max _{\left(w_{1}^{d d}, p_{0}^{d d}\right)} \pi_{m 1}^{d d} & \max _{w_{2}^{d d}} \pi_{m 2}^{d d} \\
\max _{p_{1}^{d d}} \pi_{r 1}^{d d} & \max _{p_{2}^{d d}} \pi_{r 2}^{d d}
\end{array}\right.
$$

We present an optimal decision for Scenario DD in Proposition 2, and provide the detailed derivation in Appendix B. 
Proposition 2. Optimal decision in Scenario DD is as follows:

$$
\begin{aligned}
& w_{1}^{d d}=\frac{a\left(2+\beta_{1}\right)\left(2 Y_{1} \alpha+2\left(8+\beta_{1}-4 \beta_{1}^{2}\right) \beta_{2}(1-\alpha)+\alpha \beta_{2}^{2}\right)}{2 \Delta_{d d}}, w_{2}^{d d}=\frac{a\left(2+\beta_{1}\right)\left(\alpha Y_{1}+2 Y_{2}\left(1+\beta_{1}\right) \beta_{2}-\alpha\left(3+2 \beta_{1}\right) \beta_{2}^{2}\right)}{\Delta_{d d}}, \\
& \left.p_{1}^{d d}=\frac{a}{2\left(2-\beta_{1}\right) \Delta_{d d}}\left[4 \alpha\left(3-\beta_{1}^{2}\right) \mathrm{Y}_{1}+2 \mathrm{Y}_{2}\left(16+11 \beta_{1}-6 \beta_{1}^{2}-4 \beta_{1}^{3}\right) \beta_{2}-\alpha\left(22+23 \beta_{1}-8 \beta_{1}^{2}-8 \beta_{1}^{3}\right) \beta_{2}^{2}\right)\right] \\
& p_{2}^{d d}=\frac{2 a\left(3-\beta_{1}^{2}\right)\left(\alpha Y_{1}+2 Y_{2}\left(1+\beta_{1}\right) \beta_{2}-\alpha\left(3+2 \beta_{1}\right) \beta_{2}^{2}\right)}{\left(2-\beta_{1}\right) \Delta_{d d}}, p_{0}^{d d}=\frac{2 a(1-\alpha)\left(16-17 \beta_{1}^{2}+4 \beta_{1}^{4}\right)+a \alpha\left(7+4 \beta_{1}\right) Y_{1} \beta_{2}}{2 \Delta_{d d}}, \\
& Q_{1}^{d d}=\frac{a\left(2 \alpha\left(2-\beta_{1}^{2}\right) Y_{1}+2 Y_{2}\left(1+\beta_{1}\right) \beta_{1} \beta_{2}-\alpha Y_{3} \beta_{2}^{2}\right)}{2\left(2-\beta_{1}\right) \Delta_{d d}}, Q_{2}^{d d}=\frac{a\left(2-\beta_{1}^{2}\right)\left(\alpha Y_{1}+2 Y_{2}\left(1+\beta_{1}\right) \beta_{2}-\alpha\left(3+2 \beta_{1}\right) \beta_{2}^{2}\right)}{\left(2-\beta_{1}\right) \Delta_{d d}}, \\
& Q_{0}^{d d}=\frac{a}{2\left(2-\beta_{1}\right) \Delta_{d d}}\left[2 \mathrm{Y}_{2}\left(\mathrm{Y}_{1} \Delta_{b m}-\left(24+17 \beta_{1}-12 \beta_{1}^{2}-8 \beta_{1}^{3}\right) \beta_{2}^{2}\right)-\alpha\left(10-\beta_{1}-4 \beta_{1}^{2}\right) \mathrm{Y}_{2} \beta_{2}-\alpha \mathrm{Y}_{4} \beta_{2}^{3}\right] \text {, } \\
& \pi_{r 1}^{d d}=\frac{a^{2}\left(2 \alpha\left(2-\beta_{1}^{2}\right) Y_{1}+2 Y_{2}\left(1+\beta_{1}\right) \beta_{1} \beta_{2}-\alpha Y_{3} \beta_{2}^{2}\right)^{2}}{4\left(2-\beta_{1}\right)^{2} \Delta_{d d^{2}}}, \\
& \pi_{r 2}^{d d}=\frac{a^{2}\left(2-\beta_{1}^{2}\right)^{2}\left[\alpha Y_{1}+2 Y_{2}\left(1+\beta_{1}\right) \beta_{2}-\alpha\left(3+2 \beta_{1}\right) \beta_{2}^{2}\right]^{2}}{\left(2-\beta_{1}\right)^{2} \Delta_{d d}{ }^{2}}, \\
& \pi_{m 1 o}^{d d}=\frac{a^{2} Y_{1}}{4\left(2-\beta_{1}\right) \Delta_{d d}{ }^{2}}\left(2(1-\alpha) \Delta_{b m}+\alpha\left(7+4 \beta_{1}\right) \beta_{2}\right)\left(2 \mathrm{Y}_{1} \mathrm{Y}_{2} \Delta_{b m}+\alpha\left(10-\beta_{1}-4 \beta_{1}^{2}\right) \mathrm{Y}_{1} \beta_{2}-2 \mathrm{Y}_{2}\left(24+17 \beta_{1}-12 \beta_{1}^{2}+8 \beta_{1}^{3}\right) \beta_{2}^{2}-\right. \\
& \left.\alpha \mathrm{Y}_{4} \beta_{2}^{3}\right) \text {, } \\
& \pi_{m 1}^{d d}=\frac{a^{2}\left(2+\beta_{1}\right)}{4\left(2-\beta_{1}\right) \Delta_{d d}^{2}}\left(2 \alpha \mathrm{Y}_{1}+2(1-\alpha)\left(8-\beta_{1}+4 \beta_{1}^{2}\right) \beta_{2}+\alpha \beta_{2}^{2}\right)\left(2 \alpha\left(2-\beta_{1}^{2}\right) \mathrm{Y}_{1}+2 \mathrm{Y}_{1} \beta_{1}\left(1+\beta_{1}\right) \beta_{2}-\alpha \mathrm{Y}_{3} \beta_{2}^{2}\right)+\pi_{m 1 o^{\prime}}^{d d} \\
& \pi_{m 2}^{d d}=\frac{a^{2}\left(2+\beta_{1}\right)\left(2-\beta_{1}^{2}\right)\left(\alpha Y_{3}+2 Y_{2}\left(1+\beta_{1}\right) \beta_{2}-\alpha\left(3+2 \beta_{1}\right) \beta_{2}^{2}\right)^{2}}{\left(2-\beta_{1}\right) \Delta_{d d}{ }^{2}}, \\
& \pi_{c 1}^{d d}=\frac{a^{2}}{\left(2-\beta_{1}\right) \Delta_{d d}{ }^{2}}\left(4 \alpha\left(3-\beta_{1}^{2}\right) \mathrm{Y}_{1}+2 \mathrm{Y}_{2}\left(16+11 \beta_{1}-6 \beta_{1}^{2}-4 \beta_{1}^{3}\right) \beta_{2}-\alpha\left(22+23 \beta_{1}-8 \beta_{1}^{2}+\beta_{1}^{3}\right) \beta_{2}^{2}\right)\left(2 \alpha\left(2-\beta_{1}^{2}\right) \mathrm{Y}_{1}+2 \mathrm{Y}_{2} \beta_{1}(1+\right. \\
& \left.\left.\beta_{1}\right) \beta_{2}-\alpha Y_{3} \beta_{2}^{2}\right)+\pi_{m 10}^{d d} \\
& \pi_{c 2}^{d d}=\frac{2 a^{2}\left(3-\beta_{1}^{2}\right)\left(2-\beta_{1}^{2}\right)\left(\alpha Y_{3}+2 Y_{2}\left(2-\beta_{1}\right) \beta_{2}-\alpha\left(3+2 \beta_{1}\right) \beta_{2}^{2}\right)^{2}}{\left(2-\beta_{1}\right)^{2} \Delta_{d d}{ }^{2}} \\
& \text { where } \Delta_{d d}=16-17 \beta_{1}^{2}-4 \beta_{1}^{4}-\left(26+\beta_{1}\left(20-11 \beta_{1}-8 \beta_{1}^{2}\right)\right) \beta_{2}^{2}, \mathrm{Y}_{1}=4+\beta_{1}-2 \beta_{1}^{2}, \mathrm{Y}_{2}=(1-\alpha)\left(2-\beta_{1}\right) \text {, } \\
& \mathrm{Y}_{3}=26+23 \beta_{1}-9 \beta_{1}^{2}-8 \beta_{1}^{3}, \mathrm{Y}_{4}=58+47 \beta_{1}-20 \beta_{1}^{2}-16 \beta_{1}^{3}, \mathrm{Y}_{5}=(1-\alpha)\left(1+\beta_{1}\right) \text {. }
\end{aligned}
$$

Please note that the manufacturer $M_{1}$ receives profits from the downstream retailer and in selling products through an online channel $\left(\pi_{m 10}^{d d}\right)$. From Proposition 2, we made the following remarks:

\section{Remark 2.}

1. Market price of product from $M_{1}$ is always higher compared to $M_{2}$, because $p_{1}^{d d}-p_{2}^{d d}=$ $\frac{a \beta_{2}\left(2(1-\alpha)\left(4-\beta_{1}-2 \beta_{1}^{2}\right)+\alpha\left(7+4 \beta_{1}\right) \beta_{2}\right)}{2 \Delta_{d d}}>0$.

2. Wholesale price for first product is less compared to product at online channel, i.e., $p_{0}^{d d} \geq w_{1}^{d d}$, if $\alpha_{p}^{d d}=\frac{32\left(1-\beta_{2}\right)-2 \beta_{1}\left(17 \beta_{1}-4 \beta_{1}^{3}+10 \beta_{2}-7 \beta_{1} \beta_{2}-4 \beta_{1}^{2} \beta_{2}\right)}{4\left(3-\beta_{1}^{2}\right) Y_{3}-\left(5+4 \beta_{1}\right)\left(12-\beta_{1}-4 \beta_{1}^{2}\right) \beta_{2}+\left(2+\beta_{1}\right) \beta_{2}^{2}} \geq \alpha$.

From the above remarks, we conclude that if cross-price elasticity is too high then the retailer in the first SC may lose potential profits. Please note that market prices remain identical in Scenario BM. Therefore, the introduction of an online channel increases a degree of conflict between members in the first SC. More interestingly, the first retailer becomes more confined due to the introduction of the online channel because the price of the product in the first retail channel is always higher compared to the competitor's. Therefore, the introduction of an online channel under competition may create adverse effects to its own retailer. Next, we compare profits for the first manufacturer in Scenarios DD and BM to pinpoint whether the first manufacturer receives higher profits by introducing an online channel (Appendix F).

Proposition 3. The first manufacturer can receive higher profits in Scenario DD compared to Scenario BM, i.e., $\pi_{m 1}^{d d} \geq \pi_{m 1}^{b m}$ if $\alpha \in\left(\max \left\{0, \frac{2\left(2-\beta_{2}\right)\left(4-\beta_{2}-2 \beta_{2}^{2}\right) \phi_{1}-2 \phi_{2} \sqrt{\left(1+\beta_{2}\right)\left(2+\beta_{2}\right) \phi_{3}}}{\left(4-\beta_{2}-2 \beta_{2}^{2}\right) \phi_{4}}\right\}, \min \left\{1, \frac{2\left(2-\beta_{2}\right)\left(4-\beta_{2}-2 \beta_{2}^{2}\right) \phi_{1}+2 \phi_{2} \sqrt{\left(1+\beta_{2}\right)\left(2+\beta_{2}\right) \phi_{3}}}{\left(4-\beta_{2}-2 \beta_{2}^{2}\right) \phi_{4}}\right\}\right)$

Please note that for analytical tractability, we assume $\beta_{1}=\beta_{2}$ in the above proposition. Graphical representations for profits for two manufacturers; and wholesale and retail prices are presented in Figure 2 where $a=300$ and $\alpha \in[0.6,1]$. 

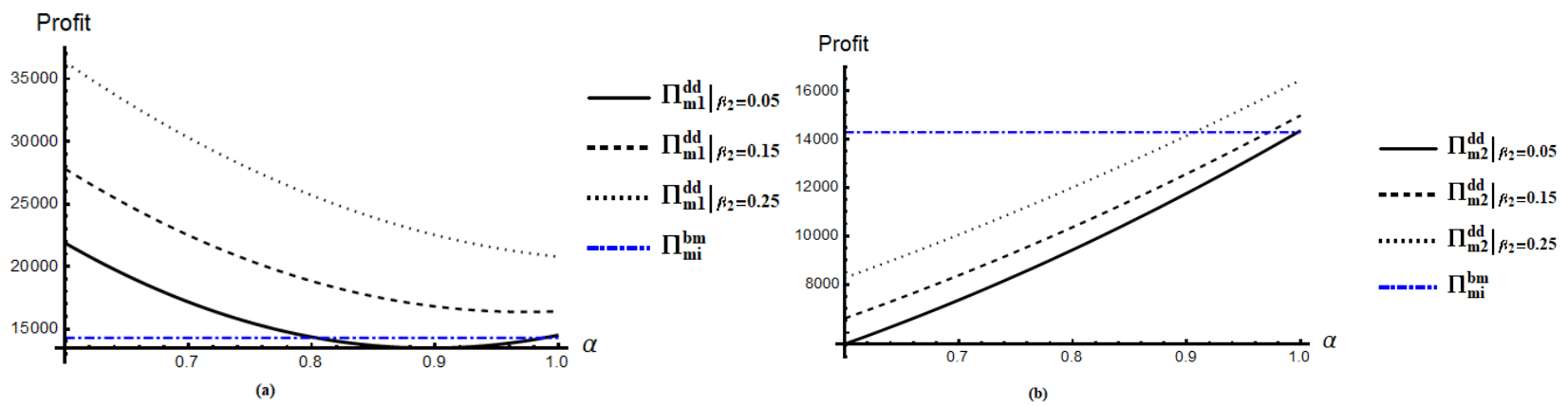

Figure 2. Profits for (a) M1 and (b) M2 for $\beta_{1}=0.15, \beta_{2} \in\{0.0,0.15,0.3\}$ in Scenarios DD and BM.

Please note that for $\beta_{1}=\beta_{2}=0.15$, the value of $\phi_{3}=-380.015<0$, i.e., the limit does not exist, and the first manufacturer always receives higher profits. Similar to the existing literature on single-manufacturer-single retailer dual-channel supply chain setting, opening an online channel is also not always profitable for the manufacturer under competition. It is expected that the retail price for the first product in the online channel decreases with an increasing value of $\alpha$, the result also supports the intuition. However, consumers are benefited if the first manufacturer opens a direct channel. Figure 2 demonstrates that retail prices are less in Scenario DD compared to BM. More interestingly, profits for both manufacturers increase with an increasing value of $\beta_{2}$. Next, we study the characteristics of SC decisions where members may be vertically integrated.

\subsection{Vertical Integration}

In this subsection, we explore the characteristics of an optimal outcomes under two possible scenarios representing the effect of vertical integration strategy between members in two competing SCs.

\section{Optimal Decision in Scenario II}

First, we discuss the scenario where both SCs are vertically integrated, i.e., in each SC upstream manufacturer and downstream retailer are integrated by a central manager. Therefore, the manager in first SC decides prices of direct $\left(p_{0}^{i i}\right)$ and retail channel $\left(p_{1}^{i i}\right)$, and the second manager decides retail price $\left(p_{2}^{i i}\right)$, respectively, by optimizing total profit for each SC. The profit functions for each vertically integrated SCs can be formulated as follows:

$$
\begin{gathered}
\Pi_{c 1}^{i i}\left(p_{0}^{i i}, p_{1}^{i i}\right)=p_{1}^{i i} D_{1}^{i i}+p_{o}^{i i} D_{o}^{i i} \\
\prod_{c 2}^{i i}\left(p_{2}^{i i}\right)=p_{2}^{i i} D_{2}^{i i}
\end{gathered}
$$

In Equation (9), the first part of the profit function for the first SC represents the profit earned from the retail channel and the second part represents the profit from the direct channel. The optimal decision in Scenario II is presented in Propositions 4 and we refer to Appendix $C$ for the detailed derivation.

Proposition 4. Optimal decision in Scenario II is obtained as follows:

$$
\begin{aligned}
& p_{0}^{i i}=\frac{a\left(2+\beta_{1}\right)\left(2 Y_{2}+3 \alpha \beta_{2}\right)}{2\left(4-\beta_{1}^{2}-\left(5+2 \beta_{1}\right) \beta_{2}^{2}\right)}, p_{1}^{i i}=\frac{a\left(\alpha\left(4+2 \beta_{1}+\beta_{2}^{2}\right)+2(1-\alpha)\left(4+\beta_{1}\right) \beta_{2}\right)}{2\left(4-\beta_{1}^{2}-\left(5+2 \beta_{1}\right) \beta_{2}^{2}\right)}, p_{2}^{i i}=\frac{a\left(\alpha\left(2+\beta_{1}-\beta_{2}^{2}\right)+2 Y_{1} \beta_{2}\right)}{4-\beta_{1}^{2}-\left(5+2 \beta_{1}\right) \beta_{2}^{2}}, Q_{1}^{i i}=\frac{a\left(\alpha\left(4+2 \beta_{1}-\left(5+3 \beta_{1}\right) \beta_{2}^{2}\right)+2 Y_{2} \beta_{1} \beta_{2}\right)}{2\left(4-\beta_{1}^{2}-\left(5+2 \beta_{1}\right) \beta_{2}^{2}\right)}, \\
& Q_{2}^{i i}=\frac{a\left(\alpha\left(2+\beta_{1}-\beta_{2}^{2}\right)+2 Y_{2} \beta_{2}\right)}{4-\beta_{1}^{2}-\left(5+2 \beta_{1}\right) \beta_{2}^{2}}, Q_{0}^{i i}=\frac{a\left(2(1-\alpha)\left(4-\beta_{1}^{2}-\left(4+\beta_{1}\right) \beta_{2}^{2}\right)+\alpha\left(2+\beta_{1}-\beta_{2}^{2}\right) \beta_{2}\right)}{2\left(4-\beta_{1}^{2}-\left(5+2 \beta_{1}\right) \beta_{2}^{2}\right)}, \pi_{c 1}^{i i}=\frac{a^{2}}{4\left(4-\beta_{1}^{2}-\left(5+2 \beta_{1}\right) \beta_{2}^{2}\right)^{2}}\left[2 \alpha\left(2+\beta_{1}\right)+2(1-\alpha)(4+\right. \\
& \left.\left.\beta_{1}\right) \beta_{2}+\alpha \beta_{2}^{2}\right)\left(2 \alpha\left(2+\beta_{1}\right)+2 Y_{2} \beta_{1} \beta_{2}-\alpha\left(5+3 \beta_{1}\right) \beta_{2}^{2}\right]+\frac{a^{2}\left(2+\beta_{1}\right)}{4\left(4-\beta_{1}^{2}-\left(5+2 \beta_{1}\right) \beta_{2}^{2}\right)^{2}}\left(2(1-\alpha)\left(2-\beta_{1}\right)+3 \alpha \beta_{2}\right)\left(2 ( 1 - \alpha ) \left(4-\beta_{1}^{2}-(4+\right.\right. \\
& \left.\left.\left.\beta_{1}\right) \beta_{2}^{2}\right)+\alpha\left(2+\beta_{1}-\beta_{2}^{2}\right) \beta_{2}\right), \pi_{c 2}^{i i}=\frac{a^{2}\left(\alpha\left(2+\beta_{1}-\beta_{2}^{2}\right)+2 Y_{2} \beta_{2}\right)^{2}}{\left(4-\beta_{1}^{2}-\left(5+2 \beta_{1}\right) \beta_{2}^{2}\right)^{2}} .
\end{aligned}
$$

From Proposition 4, we made the following remarks: 


\section{Remark 3.}

1. Total profit for the first SC is always higher compared to Second SC because $\pi_{c 1}^{i i}-\pi_{c 2}^{i i}=\frac{a^{2}\left(4(1-\alpha)^{2}\left(4-\beta_{1}^{2}\right)+4(1-\alpha) \alpha\left(4+\beta_{1}\right) \beta_{2}+3 \alpha^{2} \beta_{2}^{2}\right)}{4\left(4-\beta_{1}^{2}-\left(5+2 \beta_{1}\right) \beta_{2}^{2}\right)^{2}}>0$.

2. Market price for the first product in an online channel is higher compared to price of that in the retail channel if $\alpha \geq \frac{2\left(4-\beta_{1}^{2}-\left(4+\beta_{1}\right) \beta_{2}\right)}{12-2 \beta_{1}^{2}-\left(14-\beta_{2}\right) \beta_{2}-\beta_{1}\left(2-5 \beta_{2}\right)}$, because $p_{0}^{i i}-p_{1}^{i i}=\frac{a\left(8\left(1-\beta_{2}\right)+2 \beta_{1}\left(\beta_{1}+\beta_{2}\right)+\alpha\left(12-2 \beta_{1}^{2}+\beta_{1}\left(2-5 \beta_{2}\right)-\left(14-\beta_{2}\right) \beta_{2}\right)\right)}{2\left(4-\beta_{1}^{2}-\left(5+2 \beta_{1}\right) \beta_{2}^{2}\right)}>0$.

3. Price of the first product is always higher compared to the second product in retail channel, because $p_{1}^{i i}-p_{2}^{i i}=\frac{a \beta_{2}\left(2(1-\alpha)\left(2-\beta_{1}\right)+3 x \beta_{2}\right)}{4-\beta_{1}^{2}-\left(5+2 \beta_{1}\right) \beta_{2}^{2}}>0$.

4. Profits in the first retail channel is always less compared to the second retail channel because $p_{1}^{i i} D_{1}^{i i}-p_{2}^{i i} D_{2}^{i i}=\frac{-a^{2} \beta_{2}}{4\left(4-\beta_{1}^{2}-\left(5+2 \beta_{1}\right) \beta_{2}^{2}\right)^{2}}\left(2 Y_{2}+3 \alpha \beta_{2}\right)\left(2 \alpha \beta_{1}\left(2+\beta_{1}\right)+2(1-\alpha)\left(1+\beta_{1}\right)\left(2+\beta_{1}\right) \beta_{2}+\alpha\left(3+\beta_{1}\right) \beta_{2}^{2}\right)<0$.

If the manufacturer in first SC opens a direct channel under competition, then the total SC profit of that is always higher compared to its rival. The result makes sense as the market share of the SC with the online channel is higher. However, the profits for the first SC through retail channel is always less. Because the price of the product in the online channel is less, therefore, some consumers prefer the online channel instead of the second retail channel.

\subsection{Optimal Decision in Scenario ID}

In this scenario, members in first SC are vertically integrated by a centralized manager. Therefore, the manager decides retail prices for direct $\left(p_{0}^{i d}\right)$ and retail channel $\left(p_{1}^{i d}\right)$ by optimizing total profit for the first SC. However, the members in Second SC remain noncooperative, the manufacturer first decides wholesale price $\left(w_{2}^{i d}\right)$ and then the retailer decides retail price $\left(p_{2}^{i d}\right)$ by optimizing their respective profits. Therefore, the optimization problem is obtained as follows:

$$
\left\{\begin{array}{l}
\max _{\left(p_{1}^{i d}, p_{o}^{i d}\right)} \Pi_{c 1}^{i d}=p_{1}^{i d} D_{1}^{i d}+p_{o}^{i d} D_{o}^{i d} \max _{\tau_{2}^{i d}} \Pi_{m 2}^{i d}=w_{2}^{i d} D_{2}^{i d} \\
\left\{\begin{array}{c}
\max _{p_{2}^{i d}} \Pi_{r 2}^{i d}=\left(p_{2}^{i d}-w_{2}^{i d}\right) D_{2}^{i d}
\end{array}\right.
\end{array}\right.
$$

We present the optimal decision in the following proposition and refer to Appendix D for the detailed derivation.

Proposition 5. Optimal decision in Scenario ID is obtained as follows:

$w_{2}^{i d}=\frac{a\left(\alpha\left(4+2 \beta_{1}-\beta_{1}^{2}\right)+4 Y_{5} \beta_{2}+\alpha\left(3+2 \beta_{1}\right) \beta_{2}^{2}\right)}{\left(8-5 \beta_{1}^{2}-\left(13+10 \beta_{1}\right) \beta_{2}^{2}\right)}, p_{1}^{i d}=\frac{a\left(2 \alpha\left(4+3 \beta_{1}\right)+2(1-\alpha)\left(8+5 \beta_{1}\right) \beta_{2}+\alpha \beta_{2}^{2}\right)}{2\left(8-5 \beta_{1}^{2}-\left(13+10 \beta_{1}\right) \beta_{2}^{2}\right)}, p_{2}^{i d}=\frac{3 a\left(\alpha\left(4+2 \beta_{1}-\beta_{1}^{2}\right)+4 Y_{5} \beta_{2}+\alpha\left(3+2 \beta_{1}\right) \beta_{2}^{2}\right)}{2\left(8-5 \beta_{1}^{2}-\left(13+10 \beta_{1}\right) \beta_{2}^{2}\right)}$, $p_{0}^{i d}=\frac{2 a(1-\alpha)\left(8-5 \beta_{1}^{2}\right)+a \alpha\left(14+11 \beta_{1}\right) \beta_{2}}{2\left(8-5 \beta_{1}^{2}-\left(13+10 \beta_{1}\right) \beta_{2}^{2}\right)}, Q_{1}^{i d}=\frac{a\left(\alpha\left(4+3 \beta_{1}\right)\left(2-\beta_{1}^{2}\right)+2 Y_{5} \beta_{1} \beta_{2}+\alpha\left(13+6 \beta_{1}\left(3+\beta_{1}\right)\right) \beta_{2}^{2}\right)}{2\left(8-5 \beta_{1}^{2}-\left(13+10 \beta_{1}\right) \beta_{2}^{2}\right)}, Q_{2}^{i d}=\frac{a\left(\alpha\left(4+2 \beta_{1}-\beta_{1}^{2}\right)+4 Y_{5} \beta_{2}+\alpha\left(3+2 \beta_{1}\right) \beta_{2}^{2}\right)}{2\left(8-5 \beta_{1}^{2}-\left(13+10 \beta_{1}\right) \beta_{2}^{2}\right)}$, $Q_{0}^{i d}=\frac{a}{2\left(8-5 \beta_{1}^{2}-\left(13+10 \beta_{1}\right) \beta_{2}^{2}\right)}\left(2(1-\alpha)\left(\left(8-5 \beta_{1}^{2}\right)+3\left(4+3 \beta_{1}\right) \beta_{2}^{2}\right)+\alpha\left(6+\beta_{1}-3 \beta_{1}^{2}\right) \beta_{2}+2 \alpha\left(4+3 \beta_{1}\right) \beta_{2}^{3}\right)$, $\pi_{r 2}^{i d}=\frac{a^{2}\left(\alpha\left(4+2 \beta_{1}-\beta_{1}^{2}\right)+4 Y_{5} \beta_{2}-\alpha\left(3+2 \beta_{1}\right) \beta_{2}^{2}\right)^{2}}{4\left(8-5 \beta_{1}^{2}-\left(13+10 \beta_{1}\right) \beta_{2}^{2}\right)^{2}}, \quad \pi_{m 2}^{i d}=\frac{a^{2}\left(\alpha\left(4+2 \beta_{1}-\beta_{1}^{2}\right)+4 Y_{5} \beta_{2}-\alpha\left(3+2 \beta_{1}\right) \beta_{2}^{2}\right)^{2}}{2\left(8-5 \beta_{1}^{2}-\left(13+10 \beta_{1}\right) \beta_{2}^{2}\right)^{2}}$, $\pi_{c 1}^{i d}=\frac{a^{2}\left(2 \alpha\left(4+3 \beta_{1}\right)+2(1-\alpha)\left(8+5 \beta_{1}\right) \beta_{2}+\alpha \beta_{2}^{2}\right)}{4\left(8-5 \beta_{1}^{2}-\left(13+10 \beta_{1}\right) \beta_{2}^{2}\right)^{2}}\left[\left(\alpha\left(4+3 \beta_{1}\right)\left(2-\beta_{1}^{2}\right)+2 Y_{5} \beta_{1} \beta_{2}-\alpha\left(13+6 \beta_{1}\left(3+\beta_{1}\right)\right) \beta_{2}^{2}\right)\right]+$ $\frac{a^{2}}{4\left(8-5 \beta_{1}^{2}-\left(13+10 \beta_{1}\right) \beta_{2}^{2}\right)^{2}}\left(2(1-\alpha)\left(8-5 \beta_{1}^{2}\right)+\alpha\left(14+11 \beta_{1}\right) \beta_{2}\right)\left(2(1-\alpha)\left(8-5 \beta_{1}^{2}-3\left(4+3 \beta_{1}\right) \beta_{2}^{2}\right)+\alpha \beta_{2}\left(6+\beta_{1}-3 \beta_{1}^{2}-2 \alpha(4+\right.\right.$ $\left.\left.3 \beta_{1}\right) \beta_{2}^{2}\right), \pi_{c 2}^{i d}=\frac{3 a^{2}\left(\alpha\left(4+2 \beta_{1}-\beta_{1}^{2}\right)+4 Y_{5} \beta_{2}+\alpha\left(3+2 \beta_{1}\right) \beta_{2}^{2}\right)^{2}}{4\left(8-5 \beta_{1}^{2}-\left(13+10 \beta_{1}\right) \beta_{2}^{2}\right)^{2}}$

Based on the optimal decision in Scenario DD, we made the following remarks.

\section{Remark 4.}

1. Retail price for the first retail channel remains higher compared to the second retail channel because $p_{1}^{i d} \geq p_{2}^{i d}$ if $\alpha \leq \frac{2\left(2-\beta_{1}\right) \beta_{2}}{4-3 \beta_{1}^{2}+2\left(2-\beta_{1}\right) \beta_{2}-2\left(5+3 \beta_{1}\right) \beta_{2}^{2}}$. Sales volume for first retail channel is 


$$
\begin{aligned}
& \text { also less compared to second retail channel because } \\
& Q_{2}^{i d}-Q_{1}^{i d}=\frac{a\left(1+\beta_{1}\right)\left(\alpha\left(4-3 \beta_{1}^{2}\right)+2(1-\alpha)\left(4-\beta_{1}-2 \beta_{1}^{2}\right) \beta_{2}+\alpha\left(1+\beta_{1}^{2}\right) \beta_{2}^{2}\right)}{\left.2\left(8-5 \beta_{1}^{2}-\left(10+\beta_{1}\left(4-3 \beta_{1}\right)\right) \beta_{2}^{2}\right)\right)}>0 .
\end{aligned}
$$

2. Price of the first product in retail channel will be higher compared to the online channel,

$$
p_{1}^{i d}>p_{o}^{i d} \text { if } \alpha \leq \frac{\left(2\left(8-8 \beta_{2}-3 \beta_{1} \beta_{2}-\beta_{1}^{2}\left(5-2 \beta_{2}\right)\right)\right.}{\left.28+6 \beta_{1}-13 \beta_{1}^{2}-\left(7-2 \beta_{1}\right)\left(4+3 \beta_{1}\right) \beta_{2}-\left(3-\beta_{1}\right)\left(1+\beta_{1}\right) \beta_{2}^{2}\right)}
$$

The above remarks are also notable in the context of dual-channel supply chain literature, integration decisions can reduce the sales volume of the retail channel compared to that of competing SC. It occurs because the retail price in the first retail channel is higher compared to the second retail channel. We propose the next proposition to pinpoint whether vertical integration decisions can ensure higher total profits for each SCs (Appendix H).

\section{Proposition 6.}

(1) Total profit for the first SC is higher in Scenario II compared to BM, i.e., $\pi_{c 1}^{i i} \geq \quad \pi_{c 1}^{b m}$ if $\alpha \in\left(\max \left\{0, \frac{2\left(2-\beta_{2}\right)\left(4-\beta_{2}-2 \beta_{2}^{2}\right) \phi_{5}-4\left(1+\beta_{2}\right)\left(2-2 \beta_{2}-\beta_{2}^{2}\right) \sqrt{\phi_{6}}}{\left(2-\beta_{2}\right)\left(4-\beta_{2}-2 \beta_{2}^{2}\right)\left(40-80 \beta_{2}+44 \beta_{2}^{3}+5 \beta_{2}^{4}\right)}\right\}, \min \left\{1, \frac{2\left(2-\beta_{2}\right)\left(4-\beta_{2}-2 \beta_{2}^{2}\right) \phi_{5}+4\left(1+\beta_{2}\right)\left(2-2 \beta_{2}-\beta_{2}^{2}\right) \sqrt{\phi_{6}}}{\left(2-\beta_{2}\right)\left(4-\beta_{2}-2 \beta_{2}^{2}\right)\left(40-80 \beta_{2}+44 \beta_{2}^{3}+5 \beta_{2}^{4}\right)}\right\}\right)$

(2) Total profit for the first SC is higher in Scenario II compared to DD, i.e., $\pi_{c 1}^{i i} \geq \pi_{c 1}^{d d}$ if $\alpha \quad\left(\max \left\{0, \frac{-\left(2-\beta_{2}\right) \beta_{2} \phi_{7}+4\left(2-\beta_{2}\right) \beta_{2}\left(2-2 \beta_{2}-\beta_{2}^{2}\right) \phi_{2} \sqrt{\phi_{8}}}{\phi_{9}}\right\}, \min \left\{1, \frac{\left(2-\beta_{2}\right) \beta_{2} \phi_{7}+4\left(2-\beta_{2}\right) \beta_{2}\left(2-2 \beta_{2}-\beta_{2}^{2}\right) \phi_{2} \sqrt{\phi_{8}}}{\phi_{9}}\right\}\right)$

(3) Total profit for the first SC is higher in Scenario ID compared to Scenario BM, i.e., $\pi_{c 1}^{i d} \geq \pi_{c 1}^{b m}$ $\alpha \in\left(\max \left\{0, \frac{2\left(2-\beta_{2}\right)\left(4-\beta_{2}-2 \beta_{2}^{2}\right) \phi_{10}+4\left(4-4 \beta_{2}-5 \beta_{2}^{2}\right) \sqrt{\left(1+\beta_{2}\right) \phi_{11}}}{\left(2-\beta_{2}\right)\left(4-\beta_{2}-2 \beta_{2}^{2}\right) \phi_{12}}\right\}, \min \left\{1, \frac{2\left(2-\beta_{2}\right)\left(4-\beta_{2}-2 \beta_{2}^{2}\right) \phi_{10}+4\left(4-4 \beta_{2}-5 \beta_{2}^{2}\right) \sqrt{\left(1+\beta_{2}\right) \phi_{11}}}{\left(2-\beta_{2}\right)\left(4-\beta_{2}-2 \beta_{2}^{2}\right) \phi_{12}}\right\}\right)$

(4) Total profit for the first SC is higher in Scenario ID compared to Scenario DD, i.e., $\pi_{c 1}^{i d} \geq \pi_{c 1}^{d d}$ $\alpha \in\left(\max \left\{0, \frac{2\left(2-\beta_{2}\right) \beta_{2}^{2} \phi_{13}+4\left(2-\beta_{2}\right) \beta_{2}^{2}\left(4-4 \beta_{2}-5 \beta_{2}^{2}\right) \phi_{2} \sqrt{\left(1-\beta_{2}-\beta_{2}^{2}\right) \phi_{14}}}{\phi_{15}}\right\}, \min \left\{1, \frac{2\left(2-\beta_{2}\right) \beta_{2}^{2} \phi_{13}+4\left(2-\beta_{2}\right) \beta_{2}^{2}\left(4-4 \beta_{2}-5 \beta_{2}^{2}\right) \phi_{2} \sqrt{\left(1-\beta_{2}-\beta_{2}^{2}\right) \phi_{14}}}{\phi_{15}}\right\}\right)$

Proposition 6 demonstrates that vertical integration may ensure higher total profits compared to Scenarios DD and BM for the first SC members. Moreover, the first manufacturer has the opportunity to receive higher profits compared to Scenario DD even if the members in competing SCs remain integrated. As we have seen previously, the proportion of profits through the retail channel reduces, therefore, the downstream retailer may disagree for vertical integration if the manufacturer fails to safeguard the interests of the retailer. Graphical representations of total profit for the first and second SCs and prices in Scenarios II, ID, and BM; are presented in Figure 3.

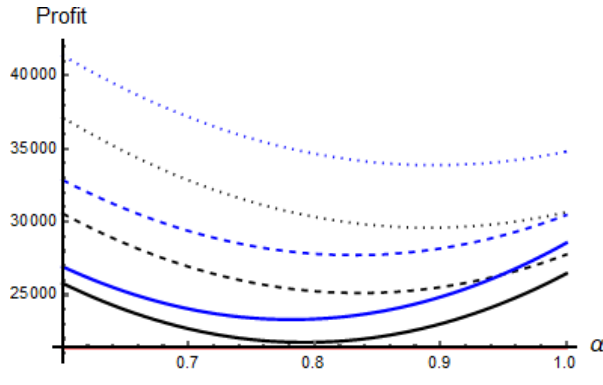

(a)

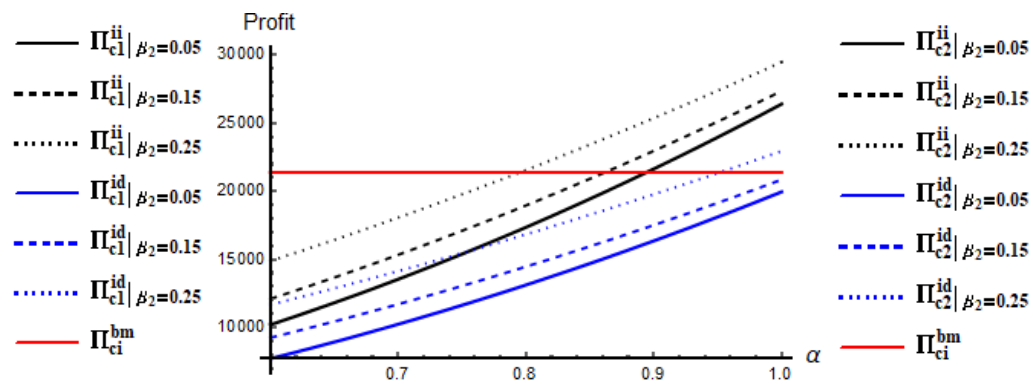

(b)

Figure 3. Profits for (a) $S C_{1}$ and (b) $S C_{2}$ for $\beta_{1}=0.15, \beta_{2} \in\{0.0,0.15,0.3\}$ in Scenarios II, ID, and BM.

From Figure 3, we made the following observations: (i) if a manufacturer opens an online channel, total profits for each SCs may be higher compared to scenario BM if cross-price elasticity between the retail and online channels is high, (ii) profits for both SCs increase with increasing cross-price elasticity $\left(\beta_{2}\right)$, (iii) Scenario ID proves to be profitable for the second SC, respectively. 
The first two observations are somewhat similar to the existing studies because with increasing cross-price elasticity, SC members can have more price differentiation power, and this generates higher profits. However, the third observation is notable, because the performance of a supply chain is expected to be increased when the members are integrated, but it does not reflect that under competition.

\subsection{Optimal Decision in Scenario UC}

Finally, we consider the effect of horizontal integration between two manufacturers or upstream collusion in the presence of an online channel ([31]). Therefore, based on the responses from their respective downstream retailers $\left(p_{1}^{u c}\right.$ and $\left.p_{2}^{u c}\right)$, two manufacturers set their respective wholesale prices $\left(w_{i}^{u c}\right)$ and the first manufacturer sets the price in the online channel by maximizing the sum of their profits, not individual profits. Therefore, the optimization problem is obtained as follows:

$$
\left\{\begin{array}{c}
\max _{\left(w_{1}^{u c}, w_{2}^{u c}, p_{o}^{u c}\right)} \pi_{m}^{u c}=\pi_{m 1}^{u c}+\pi_{m 2}^{u c} \\
\max _{p_{1}^{u c}}^{u c} \pi_{r 1}^{u c}+\max _{p_{2}^{u c}} \pi_{r 2}^{u c}
\end{array}\right.
$$

We present optimal decision in Proposition 7 , and provide the detailed derivation in Appendix E.

Proposition 7. Optimal decision in Scenario UC is obtained as follows:

$$
\begin{aligned}
& w_{i}^{u c}=\frac{a\left(\alpha+2(1-\alpha) \beta_{2}\right)}{2\left(1-\beta_{1}-2 \beta_{2}^{2}\right)}, \quad p_{i}^{u c}=\frac{a\left(2\left(2-\beta_{1}\right) \beta_{2}+\alpha\left(3-2 \beta_{1}\left(1-\beta_{2}\right)-2 \beta_{2}\left(2+\beta_{2}\right)\right)\right)}{2\left(2-\beta_{1}\right)\left(1-\beta_{1}-2 \beta_{2}^{2}\right)}, \\
& Q_{i}^{u c}=\frac{a \alpha}{2\left(2-\beta_{1}\right)} ; p_{0}^{u c}=\frac{a\left(\left(1-\beta_{1}\right)(1-\alpha)+\alpha \beta_{2}\right)}{1-\beta_{1}-2 \beta_{2}^{2}}, Q_{0}^{u c}=\frac{a\left(2-\beta_{1}-\alpha\left(2-\beta_{1}-\beta_{2}\right)\right)}{2-\beta_{1}} ; \pi_{r i}^{u c}=\frac{a^{2} \alpha^{2}}{4\left(2-\beta_{1}\right)^{2}}, \\
& \pi_{m 1 o}^{u c}=\frac{a^{2}\left(2-\beta_{1}-\alpha\left(2-\beta_{1}-\beta_{2}\right)\left(1-\beta_{1}-\alpha\left(1-\beta_{1}-\beta_{2}\right)\right)\right.}{\left(2-\beta_{1}\right)\left(1-\beta_{1}-2 \beta_{2}^{2}\right)}, \pi_{m 1}^{u c}=\frac{a^{2} \alpha\left(\alpha+2(1-\alpha) \beta_{2}\right)}{4\left(2-\beta_{1}\right)\left(1-\beta_{1}-2 \beta_{2}^{2}\right)}+\pi_{m 1 o^{\prime}}^{u c} \\
& \pi_{m 2}^{u c}=\frac{a^{2} \alpha\left(\alpha+2(1-\alpha) \beta_{2}\right)}{4\left(2-\beta_{1}\right)\left(1-\beta_{1}-2 \beta_{2}^{2}\right)}, \pi_{c 1}^{u c}=\frac{a^{2} \alpha\left(2\left(2-\beta_{1}\right) \beta_{2}+\alpha\left(3-2 \beta_{1}\left(1-\beta_{2}\right)-2 \beta_{2}\left(2+\beta_{2}\right)\right)\right.}{2\left(2-\beta_{1}\right)^{2}\left(1-\beta_{1}-2 \beta_{2}^{2}\right)}+\pi_{m 1 o^{\prime}}^{u c} \\
& \pi_{c 2}^{u c}=\frac{a^{2} \alpha\left(2\left(2-\beta_{1}\right) \beta_{2}+\alpha\left(3-2 \beta_{1}\left(1-\beta_{2}\right)-2 \beta_{2}\left(2+\beta_{2}\right)\right)\right)}{2\left(2-\beta_{1}\right)^{2}\left(1-\beta_{1}-2 \beta_{2}^{2}\right)} .
\end{aligned}
$$

Form the decision in Proposition 7, we made the following remarks:

\section{Remark 5.}

1. Unlike all four scenarios in the presence of an online channel, market prices, profits for two retailers, and wholesale prices remain identical for two competing SCs.

2. Market price of the first product is always higher in an online channel compared to a retail channel, i.e., $p_{0}^{u c} \geq p_{1}^{u c}$ if $\frac{2\left(2-\beta_{1}\right)\left(1-\beta_{1}-\beta_{2}\right)}{7+2 \beta_{1}^{2}-4 \beta_{1}\left(2-\beta_{2}\right)-2 \beta_{2}\left(4+\beta_{2}\right)} \geq \alpha$

3. Wholesale price for the first product is less compared to its price at online channel, i.e., $p_{0}^{u c} \geq w_{1}^{u c}$, if $\alpha \leq \frac{2\left(1-\beta_{1}-\beta_{2}\right)}{3-2 \beta_{1}-4 \beta_{2}}$

From the above remarks, we observe that the horizontal integration curtails a degree of conflict among competing members at the downstream level. Due to uniform wholesale prices, market prices remain the same for both products. The first manufacturer can till set a higher price at the online channel, and if they do, then the decision affects both the retailer uniformly. Consequently, their profit share remains identical, and profit through the online channel alone makes the difference. Similar to the previous subsection, we propose the following proposition to ensure whether opening an online channel is profitable for the manufacturer in Scenario UC.

Proposition 8. (1) The first manufacturer receives higher profits in Scenario UC compared to Scenario DD, i.e., $\pi_{m 1}^{u c} \geq \pi_{m 1}^{d d}$ if $\alpha \in\left(\max \left\{0, \frac{\left(2-\beta_{2}\right) \beta_{2}^{2} \phi_{16} \phi_{17}+\left(2-\beta_{2}\right) \beta_{2} \phi_{2} \sqrt{\phi_{17} \phi_{18}}}{\phi_{19}}\right\}, \min \left\{1, \frac{\left(2-\beta_{2}\right) \beta_{2}^{2} \phi_{16} \phi_{24}+\left(2-\beta_{2}\right) \beta_{2} \phi_{2} \sqrt{\phi_{17} \phi_{18}}}{\phi_{19}}\right\}\right)$ 
(2) The first manufacturer receives higher profits in Scenario UC compared to Scenario BM, i.e., $\pi_{m 1}^{u c} \geq \pi_{m 1}^{b m}$ if $\alpha \in\left(\max \left\{0, \frac{\left(2-\beta_{2}\right)\left(4-\beta_{2}-2 \beta_{2}^{2}\right)\left(8-19 \beta_{2}+8 \beta_{2}^{2}\right)+\sqrt{\left(2-\beta_{2}\right) \phi_{20}}}{\left(1-2 \beta_{2}\right)\left(4-\beta_{2}-2 \beta_{2}^{2}\right)\left(17-26 \beta_{2}+8 \beta_{2}^{2}\right)}\right\}, \min \left\{1, \frac{\left(2-\beta_{2}\right)\left(4-\beta_{2}-2 \beta_{2}^{2}\right)\left(8-19 \beta_{2}+8 \beta_{2}^{2}\right)+\sqrt{\left(2-\beta_{2}\right) \phi_{20}}}{\left(1-2 \beta_{2}\right)\left(4-\beta_{2}-2 \beta_{2}^{2}\right)\left(17-26 \beta_{2}+8 \beta_{2}^{2}\right)}\right\}\right)$

Graphical representations of the profits of each manufacturers and prices in Scenario $\mathrm{UC}$ is presented in Figure 4.

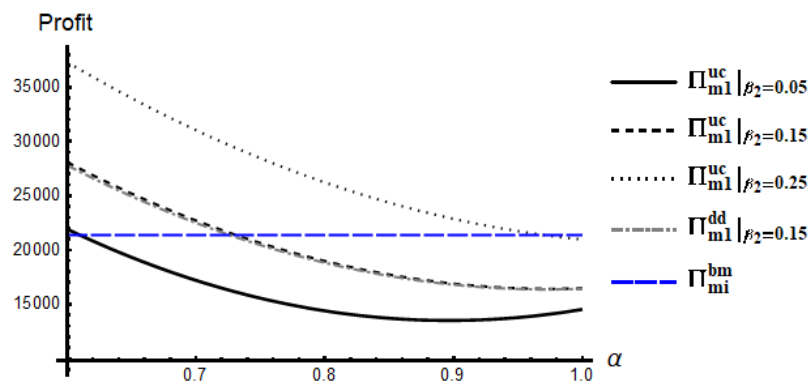

(a)

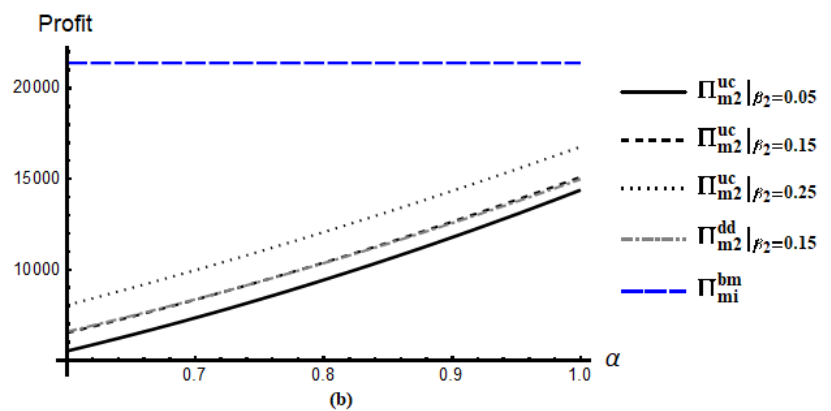

Figure 4. Profits for (a) $M_{1}$ and (b) $M_{2}$ for $\beta_{1}=0.15, \beta_{2} \in\{0.0,0.15,0.3\}$ in Scenarios UC and BM.

To sum up with results in five scenarios, the following are notable insights:

- If a competing manufacturer opens an online channel, then consumers can receive the first products at a lower price.

- If an upstream manufacturer opens an online channel, then the retailer in that SC may lose a significant amount of profit, as well as consumers in the future. Due to easy access to the internet, if consumers continuously find the product available online at a cheaper price or similar types of products in other retail outlets at a lower price, they may intend to buy the product online or change their minds in the future.

- All the competing members have the opportunity to receive a higher profit in the presence of an online channel compared to Scenario BM. Due to the additional price option and consumer cross-price elasticity, members are somehow bound to reduce the price for the products. Consequently, demand increases and total profit also increases.

- Both horizontal and vertical integration decisions can improve total profits for each competing SCs.

Therefore, it is interesting to study that if a manufacturer opens a dual channel, which integration strategy needs to be adopted. In this following section, we analyze the issue.

\section{Result Analysis and Discussion}

\subsection{Nature of Retail Prices in Different Scenarios}

In this subsection, we identify the scenario that can yield a favorable outcome for the consumers. It is difficult to obtain an analytical relationship among prices for two products, therefore graphical representations of market prices are presented in Figure 5.

Two competitors may have decided on strategic integration with competitors or with their business partners to achieve business goals such as greater control for their decisions, to maximize profits, to ensure a higher market share, etc. In this circumstance, pricing decisions remain crucial. Please note that prices in retail channels for both products remain the same in Scenarios UC and BM. Figure 5 demonstrates that prices for the retail channel increases and the price in online channel decrease with $\alpha$. As $\alpha$ increased demand for direct channel decreased, and consequently the price fell. Retail prices for both products are less in Scenario II, which is consistent with the literature on single-retailer-singlemanufacturer SC settings. However, one notable observation is that if competing members are horizontally integrated, then customers might need to pay more. Two competing 
manufacturers cooperate for various reasons, and the results suggest that at least they can gain more price-setting power under cooperation.
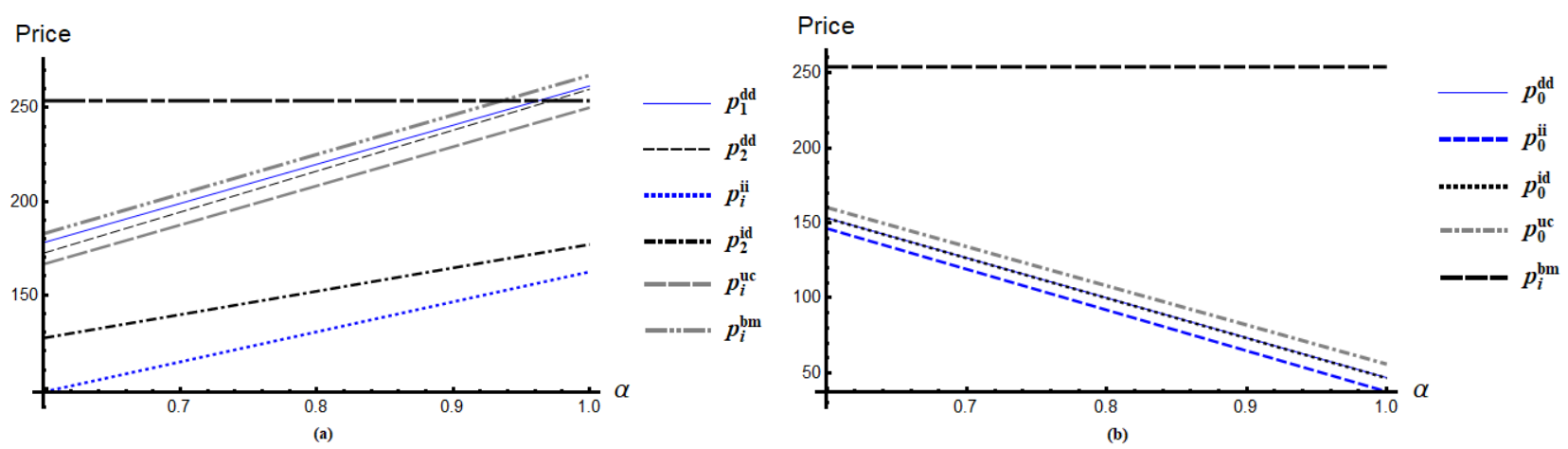

Figure 5. (a) Prices in retail channels in five scenarios for two products and (b) prices in online channels for the first product along with Scenario $\mathrm{BM}$ for $\beta_{1}=15$ and $\beta_{2}=0.15$.

\subsection{Nature Profits for Two Competing SCs in Five Scenarios}

We derive results in the absence of an online channel and refer to Appendix $G$ for the detailed.

Proposition 9. In the absence of online channel, following are true:
(i) $\Pi_{c 1}^{i d}>\max \left\{\Pi_{c 1}^{i i}, \Pi_{c 1}^{b m}, \Pi_{c 1}^{u c}\right\} \forall \beta_{1} \in(0,0.7975)$
(ii) $\prod_{c 1}^{u c}>\max \left\{\prod_{c 1,1}^{d i} \prod_{c 1}^{m m}, \prod_{c 1}^{u c}\right\} \forall \beta_{1} \in(0.7975,1)$
(iii) $\Pi_{c 1}^{b m}>\max \left\{\Pi_{c 1}^{i i}, \Pi_{c 1}^{u c}\right\} \quad \forall \beta_{1} \in(0.4323,0.7975)$
(iv) $\prod_{c 1}^{i l}>\max \left\{\Pi_{c 1}^{b m}, \Pi_{c 1}^{u c}\right\} \forall \beta_{1} \in(0,0.4323)$

Therefore, if $\beta_{1} \in(0.7975,1)$, i.e., cross-price elasticity is too high then two manufacturers can cooperate to maximize profits. If it is moderately high, $\beta_{1} \in(0.4323,0.7975)$, then the manufacturers should make the pricing decision independently, instead of upstream horizontal cooperation or the retailers at vertical levels, and if cross-price elasticity is lower $\left(\beta_{1} \in(0,0.4323)\right)$ each manufacturer can benefit from with vertical cooperation. Now the point is, whether the first manufacturers decision to open an online channel change the dynamics of equilibrium? Due to analytical complexity, we use graphical illustration to compare total profits for two SCs in the presence of a dual channel. The graphical representations for two different parameter settings are presented in Figure 6.

Figure 6 demonstrates the following key outcomes: (i) Scenario UC can prove to be a potential strategic measure for the members in the first SC, where the manufacturer also operates an online channel. (ii) Scenario BM can ensure higher profits for the second SC members. If a manufacturer opens a dual channel, some customers will prefer to buy products from online, and consequently demand for other SCs decreases. In these circumstances, it is sensible that the members in second SC prefer Scenario BM. (iii) It is observed that members in both SCs would prefer Scenario DD, where members are interested in individual profit maximization. If cross-price elasticizes are higher, then consumers would prefer an online channel due to lower prices as observed in Figure 5. (iv) Finally, it is observed that Scenario II, where members are vertically integrated, leads to lower profits.

\subsection{Managerial Insights}

The following are key insights: (i) members in each SC can receive higher profits even if one of the upstream manufacturers opens an online channel. In the literature, researchers focused on the issue of opening an online channel by neglecting the impact of SC competition. Therefore, the present study can guide to decide on opening an online channel. (ii) From Figure 6, we found that profits mainly, the first SC can be maximum in Scenario UC 
where two upstream manufacturers are horizontally integrated. Therefore, the horizontal integration strategy can serve as a profit-enhancing mechanism strategic measure for competing manufacturers. Interestingly, vertical integration leads to a sub-optimal profit, which is another interesting result of the study. Therefore, a manufacturer operating an online channel can make a deal with the competing manufacturer to safeguard the interests of both. (iii) Consumers can receive products at a lower price, especially those prefer online channel, but they need to pay more if two manufacturers cooperate horizontally.

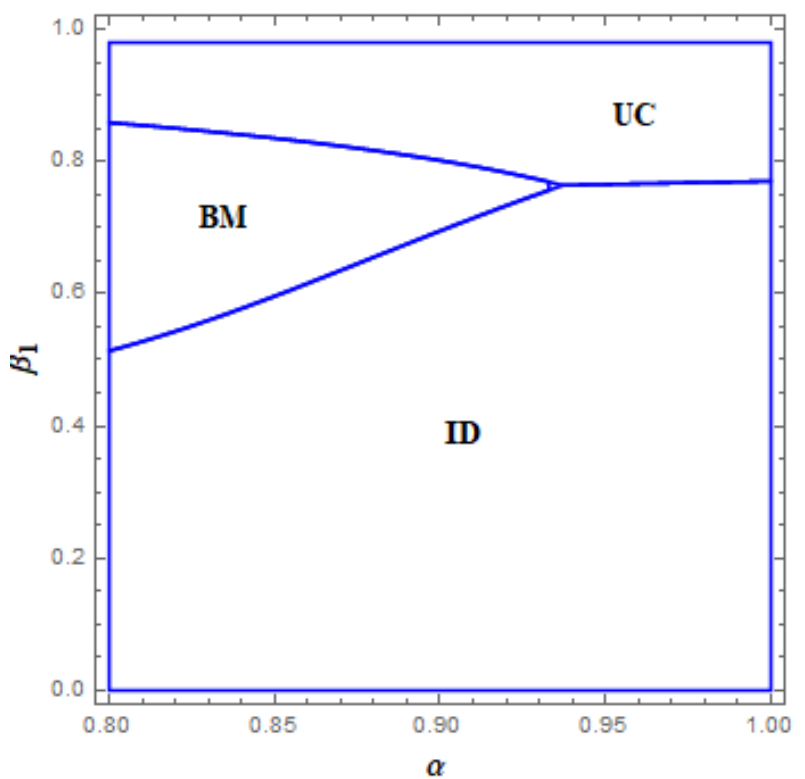

(a)

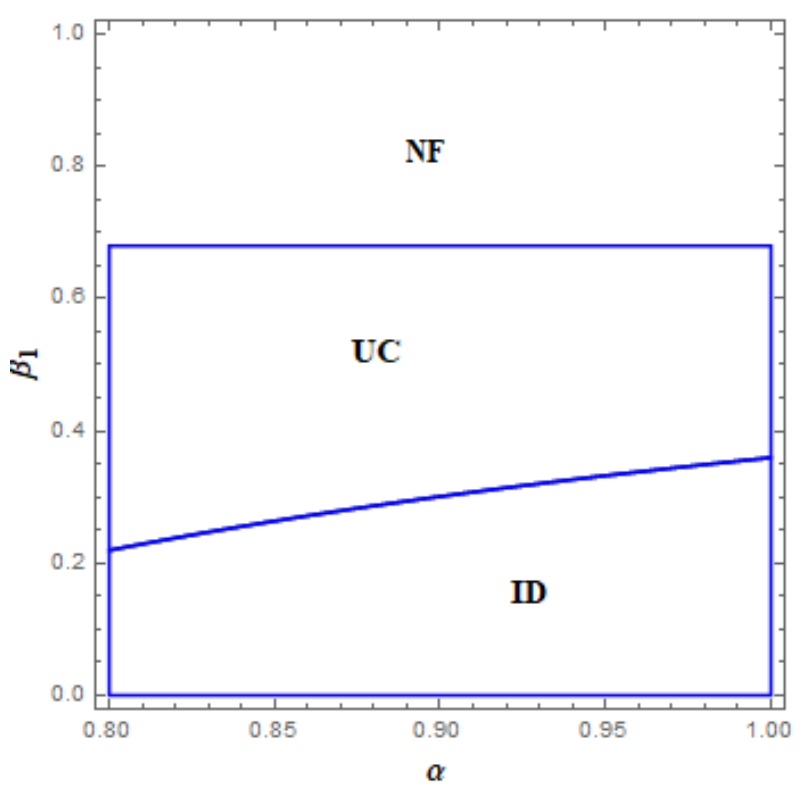

(c)

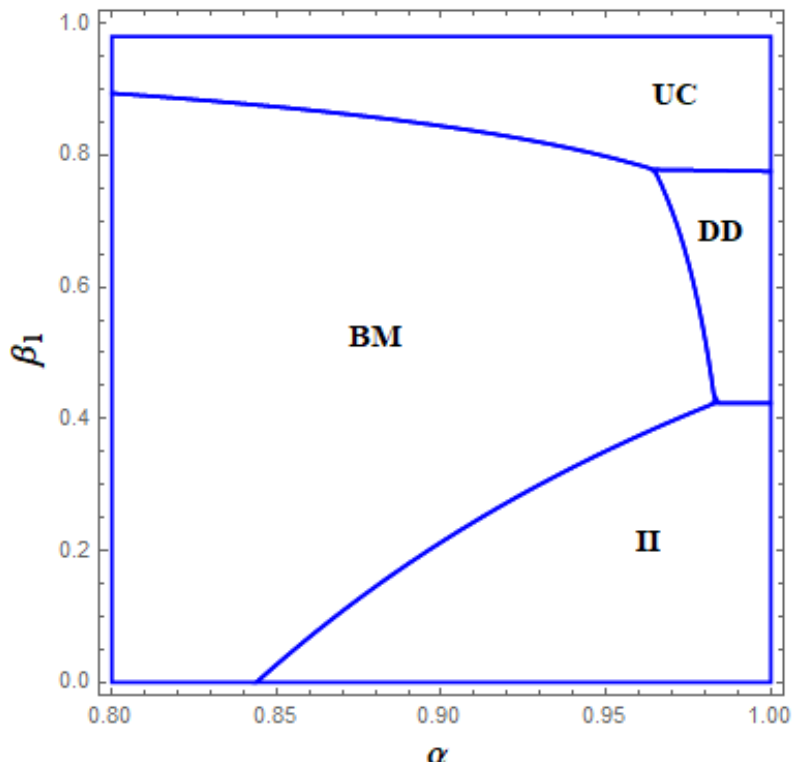

(b)

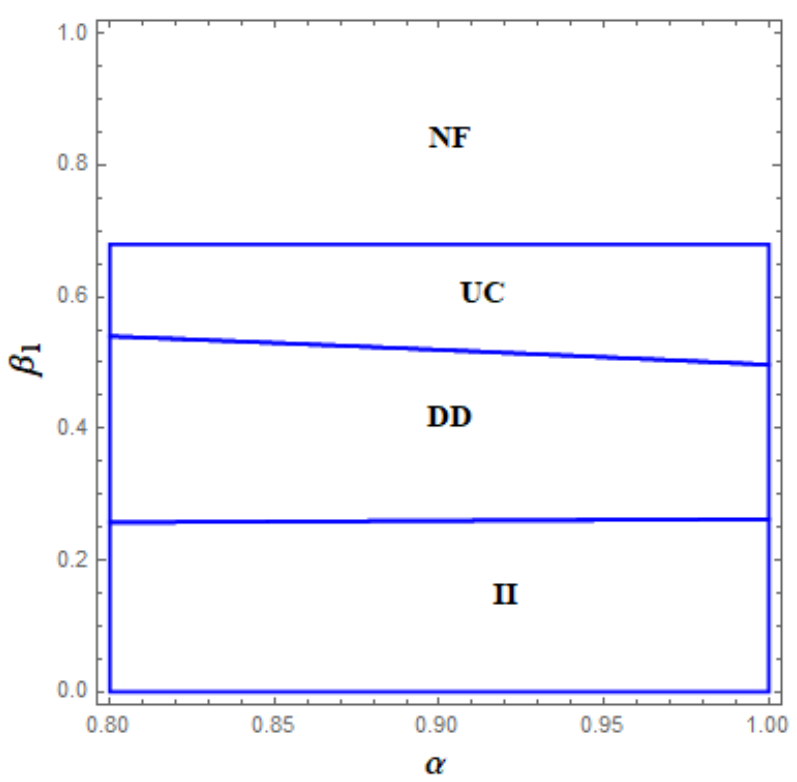

(d)

Figure 6. Total profits for (a) SC1, (b) SC2 in between Scenarios II, UC, DD, ID and BM; for $\beta_{2}=0.1$, respectively. Total profits for (c) SC1, (d) SC2 in between Scenarios II, UC, DD, ID and BM; for $\beta_{2}=0.4$, respectively $(\alpha \in(0.8,1)$, and $\left.\beta_{1} \in(0,1)\right)$. 


\section{Conclusions}

The rapid development and easy accessibility of e-commerce enable a large proportion of supply chain enterprises to sell products in a dual-channel environment. Online sales bring benefits to firms to capture a higher market share and product recognition. However, the literature on the dual-channel supply chain under competition is scanty. To complement the related research, we establish five different models to represent possible strategic integration decisions between two competing SCs, each consisting of single manufacture and an exclusive retailer. Results are compared with the benchmark model in the absence of a dual channel. The focus is to explore how pricing and strategic integration affect the performances of the two competing SCs and consumers.

We reach the following key conclusions: (1) if members of two competing SCs are vertically integrated, then consumers can receive products at the lowest price, but total profits for each SCs might not be optimal. However, vertical integration can ensure the highest SC profit in a single-manufacturer-single-retailer SC setting in the presence of a dual channel, which is not true when two manufacturers are competing with substitute products. (2) Horizontal integration between two competing manufacturers might ensure higher profits. In these circumstances, consumers need to pay more, and both the retailers can receive equal profits. Therefore, the upstream integration strategy can mitigate a degree of competition between two downstream retailers. (3) Interestingly, if one of the competing manufacturers opens an online channel, then members of competing channels might also receive higher profits, thus cross-price elasticities are the main factors affecting the preference of two SCs. However, in some parameter settings, each SC can receive higher profits if members optimize their respective profits. Till, strategic integration decisions at the upstream horizontal level or with vertical members can prove to be an efficient tool under competition, but not always.

This study still has several limitations and those need to study further. First, we do not consider the randomness of the market demand ([26]). Therefore, it is possible to study the effect of information asymmetry and demand uncertainty in any one of the scenarios, especially, when two manufacturers are horizontally integrated. For analytical tractability, we assume a uniform percentage of consumer $(\alpha)$ prefers online channels for both products. One can relax this assumption, but the analytical expression becomes complex for some scenarios. Secondly, we assume one of the manufacturers open an online channel; therefore, one can explore optimal decision when both manufacturers would open a dual channel. Finally, one can investigate the model by considering the effect of non-pricing factors such as product quality ([40,41], sales effort investment ([42]), delivery lead-time ([43]), etc. and compare outcomes.

Author Contributions: Conceptualization, S.S. and I.N.; methodology, S.S.; validation, S.S. and I.N.; writing—original draft preparation, S.S.; writing—review and editing, I.N. All authors have read and agreed to the published version of the manuscript.

Funding: This research received no external funding.

Conflicts of Interest: The authors declare no conflict of interest.

\section{Appendix A. Derivation of the Optimal Decision in Scenario BM}

Optimal decisions for two retailers are obtained by solving $\frac{d \Pi_{r i}^{b m}}{d p_{i}^{b m}}=a-2 p_{i}^{b m}+$ $w_{i}^{b m}+p_{j}^{b m} \beta_{1}=0, j=3-i, i=1,2$. On simplification, retail prices are obtained as $p_{i}^{b m}=\frac{2\left(a+w_{i}^{b m}\right)+\left(a+w_{j}^{b m}\right) \beta_{1}}{4-\beta_{1}^{2}}$, respectively. From the expression of retail prices, we observe that prices are increased with the increment of wholesale price of other products. The profit 
function for each retailer is concave because $\frac{d^{2} \Pi_{r i}^{b m}}{d p_{i}^{b m^{2}}}=-2<0$. Substituting optimal responses for the retailer, profit functions for two manufacturers are obtained as follows:

$$
\begin{gathered}
\Pi_{m i}^{b m}=\frac{w_{i}^{b m}\left(a\left(2+\beta_{1}\right)-w_{i}^{b m}\left(2-\beta_{1}^{2}\right)+w_{j}^{b m} \beta_{1}\right)}{4-\beta_{1}^{2}}, \\
j=3-i, i=1,2
\end{gathered}
$$

Therefore, optimal decisions for two manufacturers are obtained by solving $\frac{d \Pi_{m i}^{b m}}{d w_{i}^{b m}}=a\left(2+\beta_{1}\right)+w_{i}^{b m} \beta_{1}-2 w_{j}^{b m}\left(2-\beta_{1}^{2}\right)=0, j=3-i, i=1$,2. After solving, we obtain the wholesale price as presented in Proposition 1. Profit functions for each manufacturer are also concave, because $\frac{d^{2} \Pi_{m i}^{b m}}{d w_{i}^{b m^{2}}}=-\frac{2\left(2-\beta_{1}^{2}\right)}{\left(4-\beta_{1}^{2}\right)}<0$, i.e., optimal decisions always exist in this scenario.

\section{Appendix B. Derivation of the Optimal Decision in Scenario DD}

Optimal decisions for two retailers are obtained by solving $\frac{d \prod_{r i}^{d d}}{d p_{i}^{d d}}=a \alpha-2 p_{i}^{d d}+w_{i}^{d d}+$ $p_{j}^{d d} \beta_{1}+p_{0}^{d d} \beta_{2}=0, j=3-i, i=1,2$. On simplification, retail prices are obtained as $p_{i}^{d d}=\frac{a \alpha\left(2+\beta_{1}\right)+2 w_{i}^{d d}+w_{j}^{d d} \beta_{1}+p_{0}^{d d}\left(2+\beta_{1}\right) \beta_{2}}{4-\beta_{1}^{2}}$, respectively. The profit function for each retailer is concave if $\frac{d^{2} \prod_{r i}^{d d}}{d p_{i}^{d d^{2}}}=-2<0$.

Substituting optimal response for two retailers, profit functions for two manufacturers are obtained as follows: $\pi_{m 1}^{d d}=\frac{w_{1}^{d d}\left(w_{2}^{d d} \beta_{1}+\left(a \alpha+p_{0}^{d d} \beta_{2}\right)\left(2+\beta_{1}\right)-w_{1}^{d d}\left(2-\beta_{1}^{2}\right)\right)}{4-\beta_{1}^{2}}+\frac{p_{0}^{d d}\left(\left(2 a(1-\alpha)-p_{0}^{d d}\right)\left(2-\beta_{1}\right)+\left(2 a \alpha+w_{1}^{d d}+w_{2}^{d d}\right) \beta_{2}+2 p_{0}^{d d} \beta_{2}^{2}\right)}{2-\beta_{1}}$ $\pi_{m 2}^{d d} \quad=\quad \frac{a \alpha\left(2+\beta_{1}\right)+w_{1}^{d d}\left(w_{1}^{d d} \beta_{1}-w_{1}^{d d}\left(2-\beta_{1}^{2}\right)+p_{0}^{d d}\left(2+\beta_{1}\right) \beta_{2}\right)}{4-\beta_{1}^{2}}$ $\pi_{m 2}^{d d}=\frac{w_{2}^{d d}\left(a \alpha\left(2+\beta_{1}\right)+w_{1}^{d d} \beta_{1}-w_{2}^{d d}\left(2-\beta_{1}^{2}\right)+p_{0}^{d d}\left(2+\beta_{1}\right) \beta_{2}\right)}{4-\beta_{1}^{2}}$

From the expression for the profit of the second manufacturer, we observe that the profit increases if the price of the online channel increases. Therefore, wholesale prices and price for the direct channel are obtained by solving, $\frac{\partial \Pi_{m 1}^{d d}}{\partial w_{1}^{d d}}=w_{2}^{d d} \beta_{1}+a \alpha\left(2+\beta_{1}\right)-$ $2 w_{1}^{d d}\left(2-\beta_{1}^{2}\right)+2 p_{0}^{d d}\left(2+\beta_{1}\right) \beta_{2}=0 . \frac{\partial \Pi_{m 1}^{d d}}{\partial p_{0}^{d d}}=2\left(a(1-\alpha)-p_{0}^{d d}\right)\left(2-\beta_{1}\right)+\left(2 w_{1}^{d d}+w_{2}^{d d}+\right.$ $2 a \alpha) \beta_{2}+4 p_{0}^{d d} \beta_{2}^{2}=0 . i \frac{d \Pi_{m 2}^{d d}}{d w_{2}^{d d}}=w_{1}^{d d} \beta_{1}+a \alpha\left(2+\beta_{1}\right)-2 w_{2}^{d d}\left(2-\beta_{1}^{2}\right)+p_{0}^{d d}\left(2+\beta_{1}\right) \beta_{2}=0$.

On simplification, the optimal prices are presented in Proposition 2. To verify concavity, we compute the value of the Hessian matrix for the profit function for the first manufacturer as:

$$
\begin{gathered}
H_{m 1}^{d d}=\left|\begin{array}{cc}
\frac{\partial^{2} \Pi_{m 1}^{d d}}{\partial w_{1}^{d d^{2}}} & \frac{\partial^{2} \Pi_{m 1}^{d d}}{\partial p_{1}^{d d} \partial p_{0}^{d d}} \\
\frac{\partial^{2} \Pi_{m 1}^{d d}}{\partial p_{1}^{d d} \partial p_{0}^{d d}} & \frac{\partial^{2} \Pi_{m 1}^{d d}}{\partial p_{0}^{d d^{2}}}
\end{array}\right|=\left|\begin{array}{cc}
\frac{-2\left(2-\beta_{1}^{2}\right)}{4-\beta_{1}^{2}} & \frac{2 \beta_{2}}{2-\beta_{1}} \\
\frac{2 \beta_{2}}{2-\beta_{1}} & \frac{-\left(4-2 \beta_{1}+4 \beta_{2}^{2}\right.}{2-\beta_{1}}
\end{array}\right| \\
=\frac{4\left(2-\beta_{1}^{2}-\left(3+2 \beta_{1}\right) \beta_{2}^{2}\right)}{4-\beta_{2}^{2}}
\end{gathered}
$$

Because the values of the diagonal elements are negative, i.e., the profit function for the first manufacturer is concave if $2>\beta_{1}^{2}+\left(3+2 \beta_{1}\right) \beta_{2}^{2}$. The profit function for the second manufacturer is also concave because $\frac{\partial^{2} \Pi_{m 2}^{d d}}{\partial p_{2}^{d d^{2}}}=-\frac{2\left(2-\beta_{1}^{2}\right)}{4-\beta_{1}^{2}}<0$. Therefore, an optimal solution always exists if $\Delta_{d d}=16-17 \beta_{1}^{2}+4 \beta_{1}^{4}-\left(26+\beta_{1}\left(20-\beta_{1}\left(11+8 \beta_{1}\right)\right)\right) \beta_{2}^{2}>0$ and $\Delta_{d d 1}=2-\beta_{1}^{2}-\left(3+2 \beta_{1}\right) \beta_{2}^{2}>0$. 


\section{Appendix C. Derivation of the Optimal Decision in Scenario II}

To obtain the retail prices for two integrated SCs, we solve the following first order conditions simultaneously: $\quad \frac{\partial \Pi_{c 1}^{i i}}{d p_{1}^{i i}}=a \alpha+p_{2}^{i i} \beta_{1}+2 p_{0}^{i i} \beta_{2}-2 p_{1}^{i i}=0$, $\frac{\partial \Pi_{c 1}^{i i}}{d p_{0}^{i i}}=2 a(1-\alpha)+\left(2 p_{1}^{i i}+p_{2}^{i i}\right) \beta_{2}+2 p_{0}^{i i}=0, \frac{d \Pi_{c 2}^{i i}}{d p_{2}^{i j}}=a \alpha+p_{1}^{i i} \beta_{1}+2 p_{0}^{i i} \beta_{2}-2 p_{2}^{i i}=0$, On simplification, we present the optimal prices in Proposition 4 . To verify concavity, we compute the value of the Hessian matrix for the profit function of first SC as:

$$
H_{c 1}^{i i}=\left|\begin{array}{cc}
\frac{\partial^{2} \Pi_{c 1}^{i i}}{\partial p_{1}^{i 2}} & \frac{\partial^{2} \Pi_{c 1}^{i i}}{\partial p_{1}^{i j} \partial_{0}^{i i}} \\
\frac{\partial^{2} \Pi_{c 1}^{i i}}{\partial p_{1}^{i c} \partial p_{0}^{i i}} & \frac{\partial^{2} \Pi_{c}^{i i}}{\partial p_{0}^{i i^{2}}}
\end{array}\right|=\left|\begin{array}{cc}
-2 & \beta_{2} \\
\beta_{2} & -2
\end{array}\right|=4-\beta_{2}^{2}>0
$$

Because the value of the diagonal elements is negative and the value of the determinant is positive, i.e., the profit function for the first SC is concave. The profit function for the second SC is also concave because $\frac{d^{2} \Pi_{c 2}^{i i}}{d p_{2}^{i 2}}=-2<0$. Therefore, optimal solutions always exist. From the expressions, of the optimal decision, we can conclude that a feasible solution exists if $4>\beta_{1}^{2}+\left(5+2 \beta_{1}\right) \beta_{2}^{2}$.

\section{Appendix D. Derivation of the Optimal Decision in Scenario ID}

Optimal response for the second retailer is obtained by solving $\frac{d \Pi_{r 2}^{i d}}{d p_{2}^{i d}}=0$. On simplification, response on retail price is obtained as $p_{2}^{i d}=\frac{w_{2}^{i d}+a \alpha+p_{1}^{i d} \beta_{1}+p_{0}^{i d} \beta_{2}}{2}$. The profit function for the second retailer is concave because $\frac{d^{2} \Pi_{r 2}^{i d}}{d p_{2}^{i d^{2}}}=-2<0$. Substituting optimal responses, profit function for the first manufacturer and total profits for the second SC are obtained as follows:

$\Pi_{m 2}^{i d}=\frac{w_{2}^{i d}\left(a \alpha-w_{2}^{i d}+p_{1}^{i d} \beta_{1}+p_{0}^{i d} \beta_{2}\right)}{2}$

$\Pi_{c 1}^{i d}=\frac{1}{2}\left[a\left(p_{1}^{i d} \alpha\left(2+\beta_{1}\right)+p_{0}^{i d}\left(4-4 \alpha+\alpha \beta_{2}\right)\right)+p_{0}^{i d}\left(w_{2}^{i d}+2 p_{1}^{i d}\left(2+\beta_{1}\right)\right) \beta_{2}-\left(p_{1}^{i d^{2}}+p_{0}^{i d^{2}}\right)\left(2-\beta_{2}^{2}\right)+\beta_{1} p_{1}^{i d} w_{2}^{i d}\right]$

Therefore, optimal prices for first SC and second manufacturer are obtain by solving $\frac{\partial \Pi_{c 1}^{i d}}{\partial p_{1}^{i d}}=0, \frac{\partial \Pi_{c 1}^{i d}}{\partial p_{0}^{b m}}=0$, and $\frac{d \Pi_{m 2}^{d i}}{d p_{2}^{m b}}=0$. After solving, we obtain prices as presented in Proposition 5. To verify concavity, we compute the value of the Hessian matrix for the first SC as:

$$
\begin{gathered}
H_{c 1}^{i d}=\left|\begin{array}{cc}
\frac{\partial^{2} \Pi_{c 1}^{i d}}{\partial p_{1}^{2}} & \frac{\partial^{2} \Pi_{c 1}^{i d}}{\partial p_{1}^{i d} \partial p_{0}^{i d}} \\
\frac{\partial^{2} \Pi_{c 1}^{i d}}{\partial p_{1}^{i d} p_{0}^{i d}} & \frac{\partial^{2} \Pi_{c 1}^{i d}}{\partial p_{0}^{i d^{2}}}
\end{array}\right|=\left|\begin{array}{cc}
-\left(2-\beta_{1}^{2}\right) & \left(2+\beta_{1}\right) \beta_{2} \\
\left(2+\beta_{1}\right) \beta_{2} & -\left(2-\beta_{2}^{2}\right)
\end{array}\right| \\
=2\left(2-\beta_{1}^{2}-\left(3+2 \beta_{1}\right) \beta_{2}^{2}\right) .
\end{gathered}
$$

Thus, each diagonal element is negative, i.e., the profit function for the first SC is concave if $2>\beta_{1}^{2}+\left(3+2 \beta_{1}\right) \beta_{2}^{2}$. The profit function for the second manufacturer is also concave because $\frac{\partial^{2} \Pi_{m 2}^{i d}}{\partial w_{2}^{i 2^{2}}}=-1<0$. Therefore, the optimal decision exists in Scenario ID.

\section{Appendix E. Derivation of the Optimal Decision in Scenario UC}

Optimal response for two retailers remains same as in Scenario DD, and the corresponding profit functions for two manufacturers are obtained as follows: $\Pi_{m 1}^{u c}=\frac{w_{1}^{u c}\left(w_{2}^{u c} \beta_{1}+\left(a \alpha+p_{0}^{u c} \beta_{2}\right)\left(2+\beta_{1}\right)-w_{1}^{u c}\left(2-\beta_{1}^{2}\right)\right)}{4-\beta_{1}^{2}}+\frac{p_{0}^{u c}\left(\left(2 a(1-\alpha)-p_{0}^{u c}\right)\left(2-\beta_{1}\right)+\left(2 a \alpha+w_{1}^{u c}+w_{2}^{u c}\right) \beta_{2}+2 p_{0}^{u c} \beta_{2}^{2}\right)}{2-\beta_{1}}$, $\Pi_{m 2}^{u c}=\frac{w_{1}^{u c}\left(w_{1}^{u c} \beta_{1}+a \alpha\left(2+\beta_{1}\right)-w_{1}^{u c}\left(2-\beta_{1}^{2}\right)+p_{0}^{u c}\left(2+\beta_{1}\right) \beta_{2}\right)}{4-\beta_{1}^{2}}$ 
However, two manufacturers optimize the sum of upstream profit $\left(\Pi_{m}^{u c}=\Pi_{m 1}^{u c}+\Pi_{m 2}^{u c}\right)$. Therefore, wholesale prices and price for the direct channel is obtained by solving, $\frac{\partial \prod_{m}^{u c}}{\partial w_{1}^{c c}}=$ $2 w_{2}^{u c} \beta_{1}+a \alpha\left(2+\beta_{1}\right)-2 w_{2}^{u c}\left(2-\beta_{1}^{2}\right)+2 p_{0}^{u c}\left(2+\beta_{1}\right) \beta_{2}=0$.

$$
\begin{aligned}
& \frac{\partial \Pi_{m}^{u c}}{\partial w_{2}^{u c}}=w_{1}^{u c} \beta_{1}+a \alpha\left(2+\beta_{1}\right)-2 w_{2}^{u c}\left(2-\beta_{1}^{2}\right)+2 p_{0}^{u c}\left(2+\beta_{1}\right) \beta_{2}=0 . \\
& \frac{\partial \Pi_{m}^{m d}}{\partial p_{0}^{u c}}=2\left(a(1-\alpha)+p_{0}^{u c}\right)\left(2-\beta_{1}\right)+2\left(w_{1}^{u c}+w_{2}^{u c}+a \alpha\right) \beta_{2}+4 p_{0}^{u c} \beta_{2}^{2}=0 .
\end{aligned}
$$

On simplification, we obtained the optimal decision as presented in Proposition 7. To verify the concavity of joint profits for two upstream manufacturers, we compute the Hessian matrix as follows:

$$
\begin{gathered}
H_{m i}^{u c}=\left[\begin{array}{ccc}
\frac{\partial^{2} \Pi_{m}^{u c}}{\partial w_{1}^{u c}} & \frac{\partial^{2} \Pi_{m}^{u c}}{\partial w_{1}^{u c} \partial w_{2}^{u c}} & \frac{\partial^{2} \Pi_{m}^{u c}}{\partial w_{1}^{u c} \partial p_{0}^{u c}} \\
\frac{\partial^{2} \Pi_{m}^{u c}}{\partial w_{1}^{u c} \partial w_{2}^{u c}} & \frac{\partial^{2} \Pi_{m}^{u c}}{\partial w_{2}^{u c}} & \frac{\partial^{2} \Pi_{m}^{u c}}{\partial w_{2}^{u c} \partial p_{0}^{u c}} \\
\frac{\partial^{2} \Pi_{m}^{u c}}{\partial w_{1}^{u c} \partial p_{0}^{u c}} & \frac{\partial^{2} \Pi_{m}^{u c}}{\partial w_{2}^{u c} \partial p_{0}^{u c}} & \frac{\partial^{2} \Pi_{m}^{u c}}{\partial p_{0}^{u c}}
\end{array}\right] \\
=\left[\begin{array}{ccc}
\frac{-2\left(2-\beta_{1}^{2}\right)}{4-\beta_{1}^{2}} & \frac{2 \beta_{1}}{4-\beta_{1}^{2}} & \frac{2 \beta_{2}}{2-\beta_{1}} \\
\frac{-2 \beta_{1}}{4-\beta_{1}^{2}} & \frac{-2\left(2-\beta_{1}^{2}\right)}{4-\beta_{1}^{2}} & \frac{2 \beta_{2}}{2-\beta_{1}} \\
\frac{2 \beta_{2}}{2-\beta_{1}} & \frac{2 \beta_{2}}{2-\beta_{1}} & \frac{-\left(4-2 \beta_{1}+4 \beta_{2}^{2}\right)}{2-\beta_{1}}
\end{array}\right]
\end{gathered}
$$

The values of principle are $H_{m 1}^{u c}=\frac{-2\left(2-\beta_{1}^{2}\right)}{4-\beta_{1}^{2}}, H_{m 2}^{u c}=\frac{4\left(1-\beta_{1}^{2}\right)}{\left(4-\beta_{1}^{2}\right)}$, and $H_{m 3}^{u c}=\frac{-8\left(1+\beta_{1}\right)\left(1-\beta_{1}-2 \beta_{2}^{2}\right)}{\left(4-\beta_{1}^{2}\right)}$, respectively. Therefore, the joint profit function for two upstream manufacturers is concave and the optimal decision in Scenario MC exists if $1>\beta_{1}+2 \beta_{2}^{2}$.

\section{Appendix F. Prof of Proposition 3}

We can represent the difference between profits for the first manufacturer in Scenario DD and BM as $\Pi_{m 1}^{d d}-\Pi_{m 1}^{b m}=\frac{a^{2}\left(\lambda_{1} \alpha^{2}+\lambda_{2} \alpha+\lambda_{3}\right)}{4\left(2-\beta_{2}\right)\left(1+\beta_{2}\right)\left(4-\beta_{2}-2 \beta_{2}^{2}\right)^{2}\left(16-\beta_{2}\left(16+\beta_{2}\left(27-\beta_{2}\left(7+8 \beta_{2}\right)\right)\right)\right)^{2}}$, where $\lambda_{1}=\left(4-\beta_{2}-2 \beta_{2}^{2}\right)^{2}\left(2304-6656 \beta_{2}-1616 \beta_{2}^{2}+15176 \beta_{2}^{3}-1474 \beta_{2}^{4}-12601 \beta_{2}^{5}+1167 \beta_{2}^{6}+\right.$ $\left.4296 \beta_{2}^{7}-192 \beta_{2}^{8}-512 \beta_{2}^{9}\right) ; \lambda_{2}=4\left(2-\beta_{2}\right)\left(4-\beta_{2}-2 \beta_{2}^{2}\right)^{2}\left(512-960 \beta_{2}-1280 \beta_{2}^{2}+2048 \beta_{2}^{3}+\right.$ $\left.1577 \beta_{2}^{4}-1197 \beta_{2}^{5}-784 \beta_{2}^{6}+208 \beta_{2}^{7}+128 \beta_{2}^{8}\right) ;$ and $\lambda_{3}=4\left(7168-15872 \beta_{2}-13440 \beta_{2}^{2}+\right.$ $46400 \beta_{2}^{3}+5820 \beta_{2}^{4}-57710 \beta_{2}^{5}+1046 \beta_{2}^{6}+37252 \beta_{2}^{7}-706 \beta_{2}^{8}-12751 \beta_{2}^{9}-147 \beta_{2}^{10}+2128 \beta_{2}^{11}+$ $\left.64 \beta_{2}^{12}-128 \beta_{2}^{13}\right)$.

Now, $\lambda_{1} \alpha^{2}+\lambda_{2} \alpha+\lambda_{3}=\lambda_{1}\left(\alpha+\frac{\lambda_{2}}{2 \lambda_{1}}\right)^{2}+\frac{4 \lambda_{3} \lambda_{1}-\lambda_{2}^{2}}{4 \lambda_{1}}$, profits for the manufacturer always satisfy $\Pi_{m 1}^{d d} \geq \Pi_{m 1}^{b m}$ if $4 \lambda_{3} \lambda_{1}>\lambda_{2}^{2}$, and otherwise we obtain the range shown in Proposition 3.

\section{Appendix G. Optimal Decision in the Absence of Online Channel}

Optimal decisions in Scenarios BM, II, DI, and ID in the absence of an online channel. Please note that the optimal decisions remain identical in Scenario BM and DD in the absence of an online channel. By comparing profits for each SC, we obtain the following:

$$
\begin{aligned}
& \Pi_{c 1}^{i i}-\Pi_{c 1}^{u c}=\frac{a^{2}\left(1-2 \beta_{1}\right)}{4\left(2-\beta_{1}\right)^{2}\left(1-\beta_{1}\right)}>0 \forall \beta_{1} \in(0,0.5) \\
& \Pi_{c 1}^{i i}-\Pi_{c 1}^{b m}=\frac{a^{2}\left(2+\beta_{1}\right)\left(2-5 \beta_{1}+2 \beta_{1}^{3}\right)}{\left(2-\beta_{1}\right)^{2}\left(4-\beta_{1}-2 \beta_{1}^{2}\right)^{2}}>0 \forall \beta_{1} \in(0,0.4323) \\
& \Pi_{c 1}^{i i}-\Pi_{c 1}^{i d}=\frac{-a^{2} \beta_{1}\left(64+8 \beta_{1}-56 \beta_{1}^{2}+12 \beta_{1}^{3}+12 \beta_{1}^{4}-9 \beta_{1}^{5}\right)}{\left(2-\beta_{1}\right)^{2}\left(8-5 \beta_{1}^{2}\right)^{2}}<0 \forall \beta_{1} \in(0,1) \\
& \Pi_{c 1}^{b m}-\Pi_{c 1}^{u c}=\frac{a^{2} \beta_{1}\left(8-\beta_{1}\left(11+2 \beta_{1}-4 \beta_{1}^{2}\right)\right)}{4\left(2-\beta_{1}\right)^{2}\left(1-\beta_{1}\right)\left(4-\beta_{1}-2 \beta_{1}^{2}\right)^{2}}>0 \forall \beta_{1} \in(0,0.7951) \\
& \Pi_{c 1}^{i d}-\Pi_{c 1}^{u c}=\frac{a^{2}\left(64-192 \beta_{1}^{2}+32 \beta_{1}^{3}+161 \beta_{1}^{4}-50 \beta_{1}^{5}-42 \beta_{1}^{6}+18 \beta_{1}^{7}\right)}{\left.\left(2-\beta_{1}\right)^{2}\left(1-\beta_{1}\right)\left(8-5 \beta_{1}^{2}\right)^{2}\right)}>0 \forall \beta_{1} \in(0,0.7975)
\end{aligned}
$$


$\Pi_{c 1}^{i d}-\Pi_{c 1}^{b m}=\frac{a^{2}}{\left(8-5 \beta_{1}^{2}\right)^{2}\left(2-\beta_{1}\right)^{2}\left(4-\beta_{1}-2 \beta_{1}^{2}\right)^{2}}\left(512-1664 \beta_{1}^{2}-128 \beta_{1}^{3}+2032 \beta_{1}^{4}+184 \beta_{1}^{5}-1182 \beta_{1}^{6}-84 \beta_{1}^{7}+331 \beta_{1}^{8}+12 \beta_{1}^{9}-36 \beta_{1}^{10}\right)>0 \forall \beta_{1} \in(0,0.7997)$
$\Pi_{c 1}^{i d}-\Pi_{c 1}^{i d}=\frac{a^{2}\left(4-3 \beta_{1}^{2}\right)\left(4+\beta_{1}\left(12+7 \beta_{1}\right)\right)}{4\left(8-5 \beta_{1}^{2}\right)^{2}}>0 \forall \beta_{1} \in(0,1)$

Graphical representations for profit functions in the absence of an online channel is presented in Figure A1 to justify the above analytical relation.

Table A1. Optimal decision in Scenarios BM, II, DI, and ID.

\begin{tabular}{ccccc}
\hline Decision & Scenario BM/DD & Scenario II & Scenario UC & Scenario ID \\
\hline$w_{i 1}^{k}$ & $\frac{a\left(2+\beta_{1}\right)}{4-\beta_{1}-2 \beta_{1}^{2}}$ & - & $\frac{a}{2-2 \beta_{1}}$ & - \\
$w_{i 2}^{k}$ & $\frac{a\left(2+\beta_{1}\right)}{4-\beta_{1}-2 \beta_{1}^{2}}$ & - & $\frac{a}{2-2 \beta_{1}}$ & $\frac{a\left(4+\left(2-\beta_{1}\right) \beta_{1}\right)}{8-5 \beta_{1}^{2}}$ \\
$p_{i 1}^{k}$ & $\frac{2 a\left(3-\beta_{1}^{2}\right)}{\left(2-\beta_{1}\right)\left(4-\beta_{1}-2 \beta_{1}^{2}\right)}$ & $\frac{a}{2-\beta_{1}}$ & $\frac{a\left(3-2 \beta_{1}\right)}{2\left(2-3 \beta_{1}+\beta_{1}^{2}\right)}$ & $\frac{a\left(4+3 \beta_{1}\right)}{8-5 \beta_{1}^{2}}$ \\
$p_{i 2}^{k}$ & $\frac{2 a\left(3-\beta_{1}^{2}\right)}{\left(2-\beta_{1}\right)\left(4-\beta_{1}-2 \beta_{1}^{2}\right)}$ & $\frac{a}{2-\beta_{1}}$ & $\frac{a\left(3-2 \beta_{1}\right)}{2\left(2-3 \beta_{1}+\beta_{1}^{2}\right)}$ & $\frac{3 a\left(4+\left(2-\beta_{1}\right) \beta_{1}\right)}{2\left(8-5 \beta_{1}^{2}\right)}$ \\
$\pi_{r 1}^{k}$ & $\frac{a^{2}\left(2-\beta_{1}^{2}\right)^{2}}{\left(2-\beta_{1}\right)^{2}\left(4-\beta_{1}-2 \beta_{1}^{2}\right)^{2}}$ & - & $\frac{a^{2}}{4\left(2-\beta_{1}\right)^{2}}$ & - \\
$\pi_{r 2}^{k}$ & $\frac{a^{2}\left(2-\beta_{1}^{2}\right)^{2}}{\left(2-\beta_{1}\right)^{2}\left(4-\beta_{1}-2 \beta_{1}^{2}\right)^{2}}$ & - & $\frac{a^{2}}{4\left(2-\beta_{1}\right)^{2}}$ & $\frac{a^{2}\left(4+\left(2-\beta_{1}\right) \beta_{1}\right)^{2}}{4\left(8-5 \beta_{1}^{2}\right)^{2}}$ \\
$\pi_{m 1}^{k}$ & $\frac{a^{2}\left(2+\beta_{1}\right)\left(2-\beta_{1}^{2}\right)}{\left(2-\beta_{1}\right)\left(4-\beta_{1}-2 \beta_{1}^{2}\right)^{2}}$ & - & $\frac{a^{2}}{4\left(2-3 \beta_{1}+\beta_{1}^{2}\right.}$ & - \\
$\pi_{m 2}^{k}$ & $\frac{a^{2}\left(2+\beta_{1}\right)\left(2-\beta_{1}^{2}\right)}{\left(2-\beta_{1}\right)\left(4-\beta_{1}-2 \beta_{1}^{2}\right)^{2}}$ & - & $\frac{a^{2}}{4\left(2-3 \beta_{1}+\beta_{1}^{2}\right.}$ & $\frac{a^{2}\left(4+\left(2-\beta_{1}\right) \beta_{1}\right)^{2}}{2\left(8-5 \beta_{1}^{2}\right)^{2}}$ \\
$\pi_{c 1}^{k}$ & $\frac{2 a^{2}\left(6-5 \beta_{1}^{2}+\beta_{1}^{4}\right)}{\left(2-\beta_{1}\right)^{2}\left(4-\beta_{1}-2 \beta_{1}^{2}\right)^{2}}$ & $\frac{a^{2}}{\left(2-\beta_{1}\right)^{2}}$ & $\frac{a^{2}\left(3-2 \beta_{1}\right)}{4\left(2-\beta_{1}\right)^{2}\left(1-\beta_{1}\right)}$ & $\frac{a^{2}\left(4+3 \beta_{1}\right)^{2}\left(2-\beta_{1}^{2}\right)}{\left.2\left(8-5 \beta_{1}^{2}\right)^{2}\right)}$ \\
$\pi_{c 2}^{k}$ & $\frac{2 a^{2}\left(6-5 \beta_{1}^{2}+\beta_{1}^{4}\right)}{\left(2-\beta_{1}\right)^{2}\left(4-\beta_{1}-2 \beta_{1}^{2}\right)^{2}}$ & $\frac{a^{2}}{\left(2-\beta_{1}\right)^{2}}$ & $\frac{a^{2}\left(3-2 \beta_{1}\right)}{4\left(2-\beta_{1}\right)^{2}\left(1-\beta_{1}\right)}$ & $\frac{3 a^{2}\left(4+\left(2-\beta_{1}\right) \beta_{1}\right)^{2}}{4\left(8-5 \beta_{1}^{2}\right)^{2}}$ \\
\hline
\end{tabular}

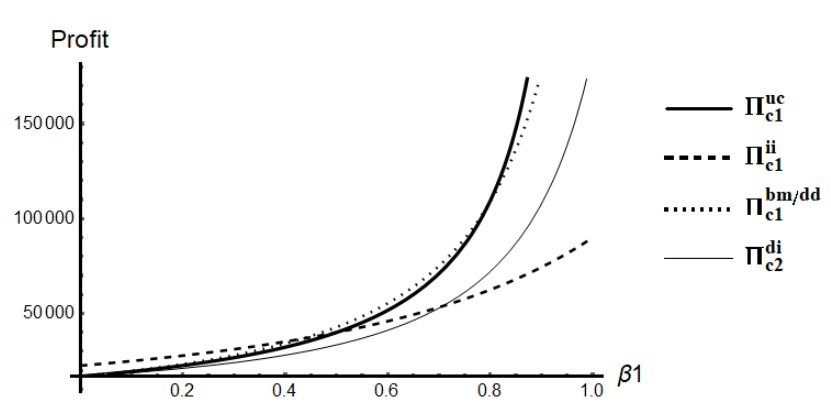

Figure A1. Total supply chain profits in the absence of dual channel.

\section{Appendix H. List of Symbols}

$\phi_{1}=512-960 \beta_{2}-1280 \beta_{2}^{2}+2048 \beta_{2}^{3}+1577 \beta_{2}^{4}-1197 \beta_{2}^{5}-784 \beta_{2}^{6}+208 \beta_{2}^{7}+128 \beta_{2}^{8}$;

$\phi_{2}=16-16 \beta_{2}-27 \beta_{2}^{2}+7 \beta_{2}^{3}+8 \beta_{2}^{4}$;

$\phi_{3}=512-7168 \beta_{2}+5216 \beta_{2}^{2}+21,904 \beta_{2}^{3}-12,356 \beta_{2}^{4}-26,018 \beta_{2}^{5}+9320 \beta_{2}^{6}+14,593 \beta_{2}^{7}-2895 \beta_{2}^{8}-3848 \beta_{2}^{9}+320 \beta_{2}^{10}$ $+384 \beta_{2}^{11}$

$\phi_{4}=2304-6656 \beta_{2}-1616 \beta_{2}^{2}+15,176 \beta_{2}^{3}-1474 \beta_{2}^{4}-12,601 \beta_{2}^{5}+1167 \beta_{2}^{6}+4296 \beta_{2}^{7}-192 \beta_{2}^{8}-512 \beta_{2}^{9}$.

$\phi_{5}=16-28 \beta_{2}-4 \beta_{2}^{2}+16 \beta_{2}^{3}+3 \beta_{2}^{4}$

$\phi_{6}=120 \beta_{2}^{2}-16-80 \beta_{2}+48 \beta_{2}^{3}-50 \beta_{2}^{4}-10 \beta_{2}^{5}-8 \beta_{2}^{6}+\beta_{2}^{7}+4 \beta_{2}^{8}$,

$\phi_{7}=1024-4480 \beta_{2}+5024 \beta_{2}^{2}+1984 \beta_{2}^{3}-5064 \beta_{2}^{4}+700 \beta_{2}^{5}+448 \beta_{2}^{6}+114 \beta_{2}^{7}+555 \beta_{2}^{8}-323 \beta_{2}^{9}-112 \beta_{2}^{10}+64 \beta_{2}^{11}$

$\phi_{8}=512-1088 \beta_{2}-208 \beta_{2}^{2}+1360 \beta_{2}^{3}-304 \beta_{2}^{4}-680 \beta_{2}^{5}+331 \beta_{2}^{6}+164 \beta_{2}^{7}-123 \beta_{2}^{8}-16 \beta_{2}^{9}+16 \beta_{2}^{10}$

$\phi_{9}=2048-3072 \beta_{2}-24,960 \beta_{2}^{2}+69,248 \beta_{2}^{3}-21,728 \beta_{2}^{4}-79,168 \beta_{2}^{5}+43,144 \beta_{2}^{6}+43,160 \beta_{2}^{7}-15,468 \beta_{2}^{8}-18,884 \beta_{2}^{9}$

$+749 \beta_{2}^{10}+5701 \beta_{2}^{11}+240 \beta_{2}^{12}-704 \beta_{2}^{13}$

$\phi_{10}=64-120 \beta_{2}-104 \beta_{2}^{2}+152 \beta_{2}^{3}+99 \beta_{2}^{4}$

$\phi_{11}=64+992 \beta_{2}-872 \beta_{2}^{2}-2464 \beta_{2}^{3}+842 \beta_{2}^{4}+1592 \beta_{2}^{5}-486 \beta_{2}^{6}-333 \beta_{2}^{7}+206 \beta_{2}^{8}+12 \beta_{2}^{9}-36 \beta_{2}^{10}$

$\phi_{12}=160-336 \beta_{2}-212 \beta_{2}^{2}+440 \beta_{2}^{3}+201 \beta_{2}^{4}-36 \beta_{2}^{5}$

$\phi_{13}=512-896 \beta_{2}-3328 \beta_{2}^{2}+6800 \beta_{2}^{3}+2840 \beta_{2}^{4}-8472 \beta_{2}^{5}-914 \beta_{2}^{6}+3299 \beta_{2}^{7}-35 \beta_{2}^{8}-368 \beta_{2}^{9}+64 \beta_{2}^{10}$

$\phi_{14}=192-64 \beta_{2}-524 \beta_{2}^{2}-40 \beta_{2}^{3}+335 \beta_{2}^{4}+23 \beta_{2}^{5}-64 \beta_{2}^{6}$ 
$\phi_{15}=8192-28,672 \beta_{2}-17,920 \beta_{2}^{2}+129,536 \beta_{2}^{3}+13,696 \beta_{2}^{4}-243,264 \beta_{2}^{5}-66,960 \beta_{2}^{6}+272,592 \beta_{2}^{7}+121,616 \beta_{2}^{8}-163,948 \beta_{2}^{9}$

$-80,499 \beta_{2}^{10}+47,653 \beta_{2}^{11}+22,604 \beta_{2}^{12}-5248 \beta_{2}^{13}+2304 \beta_{2}^{14}$

$\phi_{16}=12-19 \beta_{2}-7 \beta_{2}^{2}+8 \beta_{2}^{3}$

$\phi_{17}=32-32 \beta_{2}-45 \beta_{2}^{2}+17 \beta_{2}^{3}+16 \beta_{2}^{4}$

$\phi_{18}=8-8 \beta_{2}-17 \beta_{2}^{2}+5 \beta_{2}^{3}+8 \beta_{2}^{4}$

$\phi_{19}=256-256 \beta_{2}-1600 \beta_{2}^{2}+1760 \beta_{2}^{3}+2091 \beta_{2}^{4}-1868 \beta_{2}^{5}-1126 \beta_{2}^{6}+635 \beta_{2}^{7}+208 \beta_{2}^{8}-64 \beta_{2}^{9}$

$\phi_{20}=144-840 \beta_{2}+872 \beta_{2}^{2}+1472 \beta_{2}^{3}-1814 \beta_{2}^{4}-777 \beta_{2}^{5}+932 \beta_{2}^{6}+124 \beta_{2}^{7}-128 \beta_{2}^{8}$

\section{References}

1. Netessine, S.; Rudi, N. Supply chain choice on the internet. Manag. Sci. 2006, 52, 844-864. [CrossRef]

2. Ofek, E.; Katona, Z.; Sarvary, M. "Bricks and clicks": The impact of product returns on the strategies of multichannel retailers. Mark. Sci. 2011, 30, 42-60. [CrossRef]

3. Yan, R.; Pei, Z.; Myers, C. Do channel members value the multiple-cooperation strategy? J. Retail. Consum. Serv. 2016, 30, 84-95. [CrossRef]

4. Young, Y. US Ecommerce Sales Grow 14.9\% in 2019. 2020. Available online: www.digitalcommerce360.com/article/usecommerce-sales / (accessed on 5 July 2020).

5. Chiang, W.Y.K.; Chhajed, D.; Hess, J.D. Direct marketing, indirect profits: A strategic analysis of dual-channel supply-chain design. Manag. Sci. 2003, 49, 1-20. [CrossRef]

6. Arya, A.; Mittendorf, B.; Sappington, D.E. The bright side of supplier encroachment. Mark. Sci. 2007, 26, 651-659. [CrossRef]

7. Yan, R.; Ghose, S. Forecast information and traditional retailer performance in a dual-channel competitive market. J. Bus. Res. 2010, 63, 77-83. [CrossRef]

8. Huang, T.; Van Mieghem, J.A. Clickstream data and inventory management: Model and empirical analysis. Prod. Oper. Manag. 2014, 23, 333-347. [CrossRef]

9. Kalnins, A. Pricing variation within dual-distribution chains: The different implications of externalities and signaling for high-and low-quality brands. Manag. Sci. 2017, 63, 139-152. [CrossRef]

10. Xiao, T.; Shi, J.J. Pricing and supply priority in a dual-channel supply chain. Eur. J. Oper. Res. 2016, 254, 813-823. [CrossRef]

11. Moon, I.; Sarmah, S.P.; Saha, S. The impact of online sales on centralised and decentralised dual-channel supply chains. Eur. J. Ind. Eng. 2018, 12, 67-92. [CrossRef]

12. Chen, J.; Liang, L.; Yao, D.Q.; Sun, S. Price and quality decisions in dual-channel supply chains. Eur. J. Oper. Res. 2017, 259, 935-948. [CrossRef]

13. Dan, B.; Liu, C.; Xu, G.; Zhang, X. Pareto improvement strategy for service-based free-riding in a dual-channel supply chain. Asia Pac. J. Oper. Res. 2014, 31, 1450050. [CrossRef]

14. Rodriguez, B.; Aydın, G. Pricing and assortment decisions for a manufacturer selling through dual channels. Eur. J. Oper. Res. 2015, 242, 901-909. [CrossRef]

15. Yan, R.; Pei, Z. Retail services and firm profit in a dual-channel market. J. Retail. Consum. Serv. 2009, 16, 306-314. [CrossRef]

16. Pei, Z.; Toombs, L.; Yan, R. How does the added new online channel impact the supporting advertising expenditure? J. Retail. Consum. Serv. 2014, 21, 229-238. [CrossRef]

17. Chen, T.H. Effects of the pricing and cooperative advertising policies in a two-echelon dual-channel supply chain. Comput. Ind. Eng. 2015, 87, 250-259. [CrossRef]

18. He, Y.; Huang, H.; Li, D. Inventory and pricing decisions for a dual-channel supply chain with deteriorating products. Oper. Res. 2018, 1-43.

19. Jamali, M.B.; Rasti-Barzoki, M. A game theoretic approach for green and non-green product pricing in chain-to-chain competitive sustainable and regular dual-channel supply chains. J. Clean. Prod. 2018, 170, 1029-1043. [CrossRef]

20. Basiri, Z.; Heydari, J. A mathematical model for green supply chain coordination with substitutable products. J. Clean. Prod. 2017, 145, 232-249. [CrossRef]

21. Fang, D.; Ren, Q. Optimal decision in a dual-channel supply chain under potential information leakage. Symmetry 2019, 11, 308. [CrossRef]

22. Zhou, J.; Zhao, R.; Wang, W. Pricing decision of a manufacturer in a dual-channel supply chain with asymmetric information. Eur. J. Oper. Res. 2019, 278, 809-820. [CrossRef]

23. Wang, J.; Jiang, H.; Yu, M. Pricing decisions in a dual-channel green supply chain with product customization. J. Clean. Prod. 2020, 247, 119101. [CrossRef]

24. Saha, S.; Sarmah, S.P.; Moon, I. Dual channel closed-loop supply chain coordination with a reward-driven remanufacturing policy. Int. J. Prod. Res. 2016, 54, 1503-1517. [CrossRef]

25. Choi, S.C. Price competition in a duopoly common retailer channel. J. Retail. 1996, 72, 117-134. [CrossRef]

26. Ha, A.Y.; Tong, S. Contracting and Information Sharing Under Supply Chain Competition. Manag. Sci. 2008, 54, 701-715. [CrossRef]

27. Anderson, E.J.; Bao, Y. Price competition with integrated and decentralized supply chains. Eur. J. Oper. Res. 2010, 200, 227-234. [CrossRef] 
28. Xie, G. Modeling decision processes of a green supply chain with regulation on energy saving level. Comput. Oper. Res. 2015, 54, 266-273. [CrossRef]

29. Zhang, G.; Dai, G.; Sun, H.; Zhang, G.; Yang, Z. Equilibrium in supply chain network with competition and service level between channels considering consumers' channel preferences. J. Retail. Consum. Serv. 2020, 57, 102199. [CrossRef]

30. Garrett, B. Why Collaborating with Your Competition Can Be a Great Idea. 2019. Available online: www.forbes.com/sites/ briannegarrett/2019/09/19/why-collaborating-with-your-competition-can-be-a-great-idea/?sh=4e77f3dedf86 (accessed on 5 July 2020).

31. Wei, J.; Zhao, J.; Hou, X. Integration strategies of two supply chains with complementary products. Int. J. Prod. Res. 2019, 57, 1972-1989. [CrossRef]

32. Bian, J.; Zhao, X.; Liu, Y. Single vs. cross distribution channels with manufacturers' dynamic tacit collusion. Int. J. Prod. Econ. 2020, 220, 107456. [CrossRef]

33. Colombo, S. Mixed oligopolies and collusion. J. Econ. 2016, 118, 167-184. [CrossRef]

34. Zhou, Y.W.; Cao, Z.H. Equilibrium structures of two supply chains with price and displayed-quantity competition. J. Oper. Res. Soc. 2014, 65, 1544-1554. [CrossRef]

35. Wang, L.; Song, H.; Wang, Y. Pricing and service decisions of complementary products in a dual-channel supply chain. Comput. Ind. Eng. 2017, 105, 223-233. [CrossRef]

36. Saha, S. Channel characteristics and coordination in three-echelon dual-channel supply chain. Int. J. Syst. Sci. 2016, 47, 740-754. [CrossRef]

37. Eriksen, P.S.; Nielsen, P. Order quantity distributions: Estimating an adequate aggregation horizonautomotive industries: A SEM analysis. Manag. Prod. Eng. Rev. 2016, 7, 39-48.

38. Jafari, H.; Hejazi, S.R.; Rasti-Barzoki, M. Sustainable development by waste recycling under a three-echelon supply chain: A game-theoretic approach. J. Clean. Prod. 2017, 142, 2252-2261. [CrossRef]

39. Song, Z.; He, S.; An, B. Decision and coordination in a dual-channel three-layered green supply chain. Symmetry 2018, 10, 549. [CrossRef]

40. Nielsen, I.E.; Majumder, S.; Saha, S. Exploring the intervention of intermediary in a green supply chain. J. Clean. Prod. 2019, 233, 1525-1544. [CrossRef]

41. Nielsen, I.E.; Majumder, S.; Szwarc, E.; Saha, S. Impact of Strategic Cooperation under Competition on Green Product Manufacturing. Sustainability 2020, 12, 248. [CrossRef]

42. Saha, S.; Sarmah, S.P. Supply chain coordination under ramp-type price and effort induced demand considering revenue sharing contract. Asia Pac. J. Oper. Res. 2015, 32, 1550004. [CrossRef]

43. Michna, Z.; Disney, S.M.; Nielsen, P. The impact of stochastic lead times on the bullwhip effect under correlated demand and moving average forecasts. Omega 2020, 93, 102033. [CrossRef] 